\title{
Manzuma gen. nov., a new aelurilline genus of jumping spiders (Araneae, Salticidae)
}

\author{
Galina N. AZARKINA \\ Laboratory of Systematics of Invertebrate Animals, Institute of Systematics and Ecology of Animals \\ SB RAS, Frunze Street 11, Novosibirsk 630091, Russia. \\ Email: urmakuz@gmail.com \\ urn:lsid:zoobank.org:author:BE783F8E-0803-48B2-80A4-9D246C0F2370
}

\begin{abstract}
A new jumping spider genus, Manzuma gen. nov. (Salticidae Blackwall, 1841), is described, type species is Manzuma nigritibia (Caporiacco, 1941). Aelurillus reconditus Wesołowska \& van Harten, 1994 is synonymized with Rafalus nigritibiis (Caporiacco, 1941). Four new combinations are proposed: M. jocquei gen. et comb. nov. (ex Aelurillus), M. kenyaensis gen. et comb. nov. (ex Langelurillus), M. lympha gen. et comb. nov. (ex Rafalus) and M. nigritibia gen. et comb. nov. (ex Rafalus). Three species, M. botswana gen. et sp. nov. ( $\mathcal{T}$. , Botswana and Republic of South Africa), M. petroae gen. et

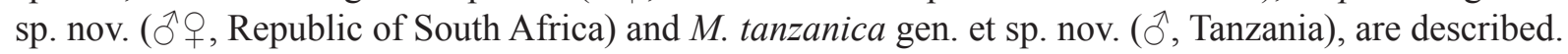
The male of $M$. kenyaensis gen. et comb. nov. and female of $M$. lympha gen. et comb. nov. are described for the first time. A new aelurilline synapomorphy is proposed. Identification key for males is provided.
\end{abstract}

Keywords. Aelurillus, new combination, new species, synapomorphy, Rafalus.

Azarkina G.N. 2019. Manzuma gen. nov., a new aelurilline genus of jumping spiders (Araneae, Salticidae). European Journal of Taxonomy 611: 1-47. https://doi.org/10.5852/ejt.2020.611

\section{Introduction}

The subtribe Aelurillina Simon, 1901 (sensu Maddison 2015) contains 288 species belonging to 9 genera; this subtribe is the most speciose among tribe Aelurillini Simon, 1901 which otherwise includes 189 species and 26 genera in Freyina Edwards, 2015 and 62 species and 14 genera in Thiratoscirtina Bodner \& Maddison, 2012 (WSC 2019). Five of the subtribe's genera were recently revised, described or reviewed: Aelurillus Simon, 1884 (Azarkina 2006), Asianellus Logunov \& Heçiak, 1996 (Logunov \& Heçiak 1996), Langelurillus Próchniewicz, 1994 (Próchniewicz, 1994), Proszynskiana Logunov, 1996 (Logunov 1996a) and Stenaelurillus (Wesołowska 2014a, 2014b; Logunov \& Azarkina 2018). Four genera, Langona Simon, 1901, Phanuelus Caleb \& Mathai, 2015, Phlegra Simon, 1876 and Rafalus Prószyński, 1999, remain in need of revision.

The genus Rafalus Prószyński, 1999 contains twelve species, distributed mainly in West Asia and Africa although two species are known from Middle Asia and Bhutan (WSC 2019). According to Prószyński (1999), Rafalus can be distinguished from other members of Aelurillina, such as Aelurillus Simon, 1884, 
Langona Simon, 1901 and Phlegra Simon, 1876, by the following characters: (1) palpal tibia with one retrolateral apophysis and without a bunch of stiff setae; (2) female epigyne with two indistinct posterior openings, ducts long and broad, S-like bent, very small spermathecae located transversely; (3) legs III are the longest (rarely about equal to legs IV); and (4) higher, convex cephalothorax.

In his paper, Prószyński (1999) described four news species: R. christophori Prószyński, 1999 (đ̊̊), R. feliksi Prószyński, 1999 (đ̊T), R. karskii Prószyński, 1999 () and R. stanislawi Prószyński, 1999 (ð); he also provided five new combinations: R. insignipalpis (Simon, 1882) (ð゚), R. lymphus (Próchniewicz \& Hęciak, 1994) (す), R. nigritibiis (Caporiacco, 1941) (す), R. variegatus (Kroneberg, 1875) ( $\overbrace{}^{\lambda}+$ ) and $R$. wittmeri (Prószyński, 1978) ( $\overbrace{}^{\Uparrow})$. Wesołowska \& van Harten (2010) described three new species of Rafalus from the United Arab Emirates: $R$. arabicus Wesołowska \& van Harten, 2010

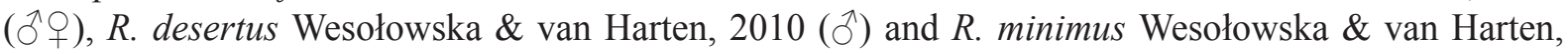
2010 (ठ). One year later Wesołowska \& Russell-Smith (2011) described Aelurillus jocquei Azarkina, Wesołowska \& Russell-Smith, 2011 (ðㅇ) from Nigeria with remarks that "The species only tentatively is included to the genus Aelurillus. It may well represent a new genus...". Five years later Dawidowicz \& Wesołowska (2016) described Langelurillus kenyaensis Dawidowicz \& Wesołowska, 2016 after a single female from Kenya.

Close study of the types of Rafalus revealed that it is polyphyletic, and that $R$. lymphus and R. nigritibiis, as well as two species from the genus Aelurillus, A. jocquei and A. reconditus, and one species from Langleurillus Próchniewicz, 1994, L. kenyaensis, are quite different and belong to a new genus, which is described hereinafter. Moreover, a male from Yemen, collected not far from the type locality of A. reconditus is conspecific with the type specimen of $A$. nigritibiis, leading to the conclusion that A. reconditus is a junior synonym of $A$. nigritibiis.

The aim of the present paper are (1) to describe a new genus, Manzuma gen. nov., (2) to illustrate and redescribe four species, A. jocquei, L. kenyaensis, $R$. lymphus and $R$. nigritibiis, (3) to synonymize $A$. reconditus with $R$. nigritibiis, (4) to propose four new taxonomic combinations: $M$. jocquei gen. et comb. nov., M. kenyaensis gen. et comb. nov., M. lympha gen. et comb. nov. and M. nigritibia gen. et comb. nov., (5) to describe male of M. kenyaensis and female of M. lympha for the first time, (6) to describe three new species, M. botswana sp. nov. (§ิㅇ, from Botswana and Republic of South Africa), M. petroae gen. et sp. nov. ( $\delta^{\lambda}+$, from Republic of South Africa) and M. tanzanica gen. et sp. nov. ( ${ }^{\lambda}$, from Tanzania), (7) to provide an identification key for males, (8) to propose a new aelurilline synapomorphy retrolateral cavity in the males endites, and (9) to map the distribution of all Manzuma gen. nov. species.

\section{Materials and methods}

The specimens used in this study have been borrowed from or deposited in the following museums (curator names are in parentheses):

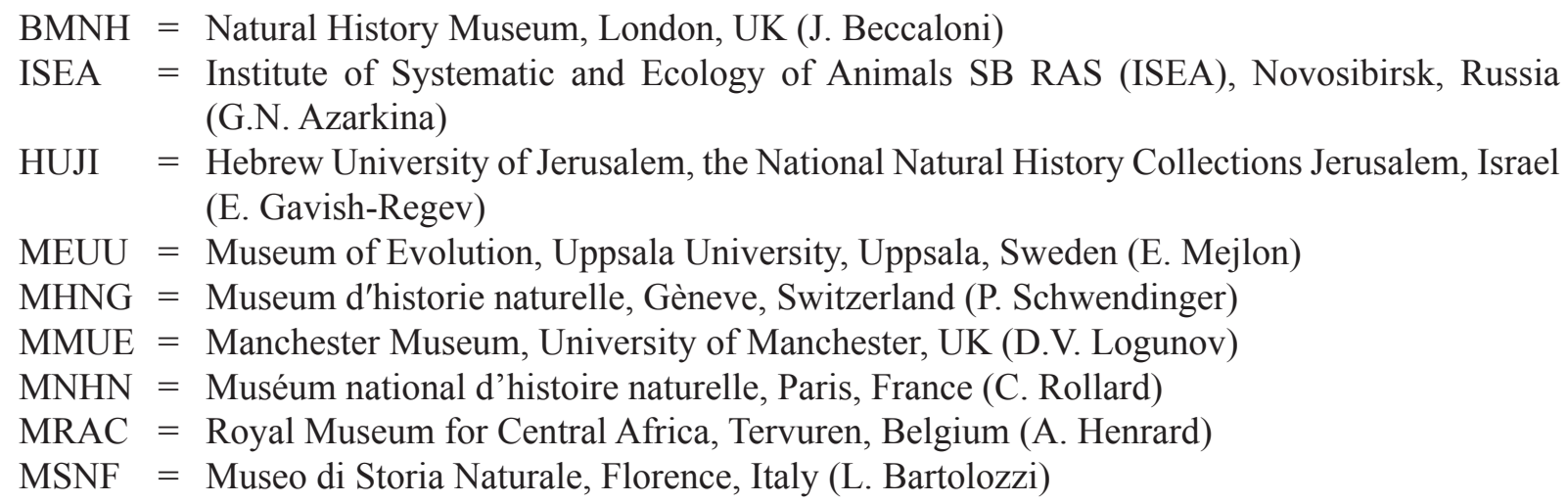




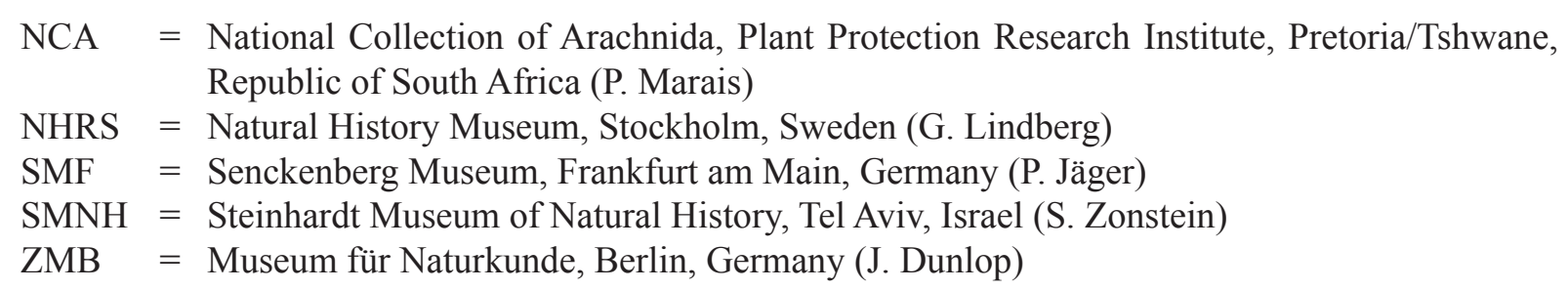

\section{Comparative material}

- Aelurillus v-insignitus (Clerck, 1757) (Figs 1-3, 8-9): RUSSIA ・ 5 ठぇં; Crimea, Skvortsovskaya

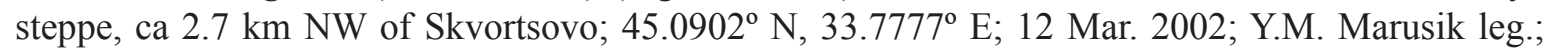
ISEA 001.8347) • 1 क ; Stavropol' Province, Manych-Gudilo Lake; ca $46.2167^{\circ} \mathrm{N}, 42.9167^{\circ} \mathrm{E}$; $4-5$ Jul. 2003; T. Khanov leg.; semidesert; ISEA, 001.8348.

- Rafalus christophori Prószyński, 1999 (Figs 4-7, 23-26): ISRAEL・Holotype đ̊; Makhtesh Ramon [=Ramon Crater], nr Shen Ramon; ca $30.5667^{\circ}$ N, 34.8500 E; 31 Jan. 1987; Y. Lubin leg.; HUJI $14237 \cdot 4$ ô ô, 1 क; Arava Valley; ca $29.9667^{\circ}$ N, 35.0500 E; 20 Apr. 2003, 8 May 2003, 30 May 2003; E. Topel leg.; SMNH.

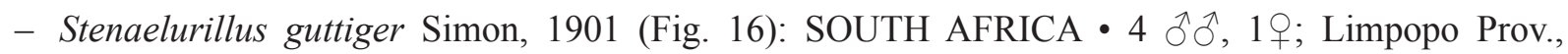
Polokwane Game Reserve; $23.9667^{\circ} \mathrm{S}, 29.4667^{\circ}$ E; 14 Nov. 2005; T.T. Khoza and M.A. Modiba leg.; woodland; active search; NCA 2008/206).

A total of 165 specimens belonging to ten species and four genera have been examined. Specimens were studied in $70 \%$ ethanol and their coloration refers to that of the preserved specimens. All drawings were made with the aid of a reticular eyepiece attached to an MBS-10 stereo microscope at ISEA and Leica M165C at SMF. Photographs were taken with a Canon EOS 550D camera attached to a Zeiss Stemi 2000-C stereo microscope at ISEA and Canon EOS 6D camera attached to Leica M165C at SMF. Stack images were combined using Helicon Focus 6.3 software. The epigynes were detached and macerated in $20 \% \mathrm{KOH}$ solution overnight. Palp expansion was accomplished by placing in $10 \%$ $\mathrm{KOH}$ for 10 minutes then placed into distilled water. SEM microphotographs were taken with SEM Hitachi TM-1000 at ISEA. Parts of spiders were dried, and then mounted on an adhesive specimen stub. After photos and drawings were taken, parts were placed in microvials and stored with specimens. All drawings were edited and assembled in Adobe Photoshop CS5. For the leg spination the system adopted is that used by Ono (1988). All measurements are in millimeters. The distributional map was compiled using the online mapping software SimpleMappr (Shorthouse 2010). The terminology follows Maddison (1996), Azarkina et al. (2018), Logunov \& Azarkina (2018) and Azarkina \& Zamani (2019).

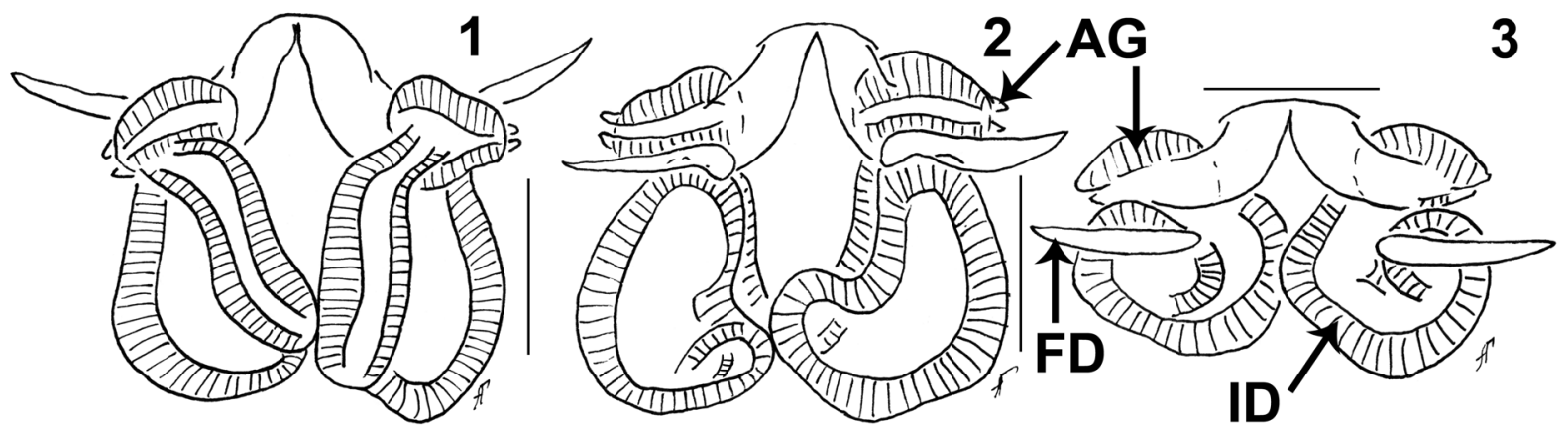

Figs 1-3. Aelurillus v-insignitus (Clerck, 1757). 1-3. Spermathecae. 1. Ventral view. 2. Dorsal view. 3. Apical view. Scale bars: $0.1 \mathrm{~mm}$. 

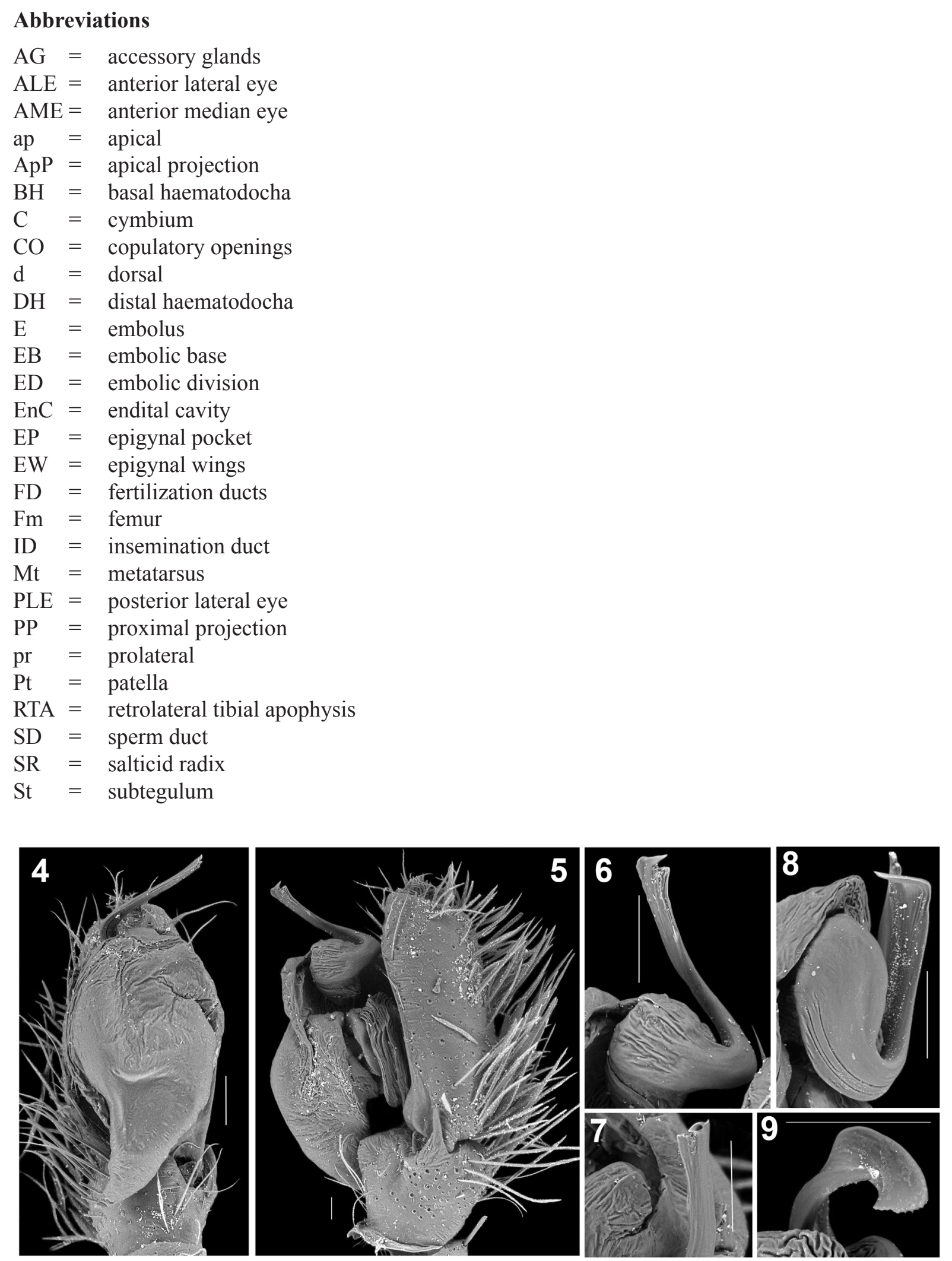

Figs 4-9. Scanning electron micrographs of Rafalus christophori Prószyński, 1999 (4-7) and Aelurillus v-insignitus (Clerck, 1757) (8-9). 4-5. Male palp. 4. Ventral view. 5. Retrolateral view. 6-9. Embolic division. 6, 8. Retrolateral view. 7, 9. Apical view. Scale bars: $0.1 \mathrm{~mm}$. 


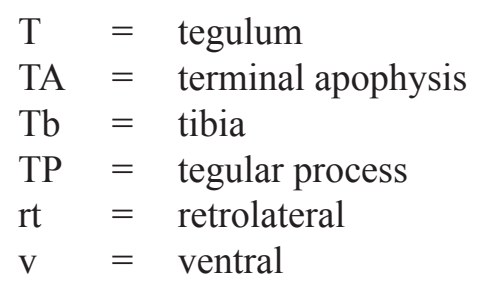

\title{
Results
}

\author{
Class Arachnida Cuvier, 1812 \\ Order Araneae Clerck, 1757 \\ Family Salticidae Blackwall, 1841 \\ Tribe Aelurillini Simon, 1901
}

Subtribe Aelurillina Simon, 1901

To date, the only synapomorphy for the subtribe Aelurillina has been suggested: viz., the presence of the deep cymbial pocket (sensu Logunov 1996a: figs 3, 4) in which the embolic division is hidden. A new good synapomorphy for the Aelurillina seems to be the presence of a small basal retrolateral cavity in the male endites (arrowed in Figs 15-17, EnC); all other salticid groups known to me lack such the cavity. Thus, the monophyly of the Aelurillina subtribe (sensu Maddison 2015) is well-supported by two good synapomorphies (both are seen in the males): the cymbial pocket and the endite cavity.

Genus Manzuma gen. nov.

urn:1sid:zoobank.org:act:B418A6A2-FA57-4C61-9F2C-B99F030471A5

\section{Type species}

Saitis nigritibiis Caporiacco, 1941, designated here.

\section{Etymology}

This genus is dedicated to my mother, Manzuma Mavlyut kyzy Azarkina. At the same time, 'manzuma' is an Islamic poetry genre from Ethiopia, the area of origin of the type species, Manzuma nigritibia gen. et comb. nov. Gender feminine.

\section{Diagnosis}

The body shape of the new genus is very similar to that of Aelurillus Simon, 1884. Manzuma differs from Aelurillus in the following characters: (1) base of the embolic division (ED) with an apical projection (Figs 52, 55, arrowed, ApP), which is absent in Aelurillus (Fig. 8); (2) the terminal apophysis (TA) is membranous and broad, situated on both pro- and retrolateral sides of the embolus, curved inwards prolaterally (Figs 56-59), while in Aelurillus the TA is more sclerotized, and connected to embolus by a membrane only on the retrolateral side (Fig. 9 and Azarkina \& Zamani 2019: figs 5-11); (3) embolic tip wide, with a short apical membranous process (Figs 56, 58), while in Aelurillus the embolus is pointed apically, without a membranous process (Figs 8-9); (4) epigynal wings are always absent, while in Aelurillus they are always present (see e.g. Azarkina 2002, 2003, 2009, etc.); (5) introductory parts of the insemination ducts are fused around the copulatory openings to form a small tube and then bifurcated (Figs 36, 67, 94, 115, 142, 164, CD), while in Aelurillus copulatory openings are always separate, even if they lie in the same epigynal depression (Figs 1-3); (6) accessory glands are short, weakly sclerotized and in most cases seen only from an apical view (Figs 35, 67, 113-115, 140-141, 164, AG), while in Aelurillus accessory glands are strongly sclerotized and in most cases visible from a dorsal view of the spermathecae (Figs 2-3, AG). 
Manzuma gen. nov. differs from Rafalus in the following characters: (1) palpal tibia without a ventral bulge, ventral RTA triangular and well developed, dorsal RTA small, rounded (Fig. 12), while in Rafalus the palpal tibia has a ventral bulge, ventral RTA triangular at the base and elongated apically, without dorsal RTA (Fig. 5); (2) base of embolic division with apical protuberance (Fig. 55, arrowed, ApP) which is absent in Rafalus (Fig. 6); (3) TA broad in Manzuma gen. nov. (Figs 56-59), narrow in Rafalus (Figs 6-7); (4) clypeus relatively high, ca. half of AME's diameter, while in Rafalus the clypeus low, about $1 / 3$ of AME's diameter (Figs 23, 26); (5) the carapace is pear-shaped, almost half as wide at AME, while in Rafalus the carapace is rectangular (Fig. 24); (6) the copulatory openings are situated in the apical part of the epigyne, with short (except for M. kenyaensis, Figs 90-91, 93) introductory parts of the insemination ducts (Figs 34, 36, 69-71, 115, 140-142, 164, 167), while in Rafalus the openings are situated near the epigastric furrow, introductory parts of the insemination ducts are long and tube-shaped (see Prószyński 1999: figs 3-4, 11-12).

Except for Aelurillus and Rafalus, all other aelurilline genera are distinct from Manzuma gen. nov. in basic body form (Langona, Langelurillus, Phlegra, Proszynskiana, Stenaelurillus) or composition of copulatory organs (e.g. coiled embolic division in Asianellus, Langona, Langelurillus, some Phlegra and Phanuelus or embolic division without apical projection in Proszynskiana).

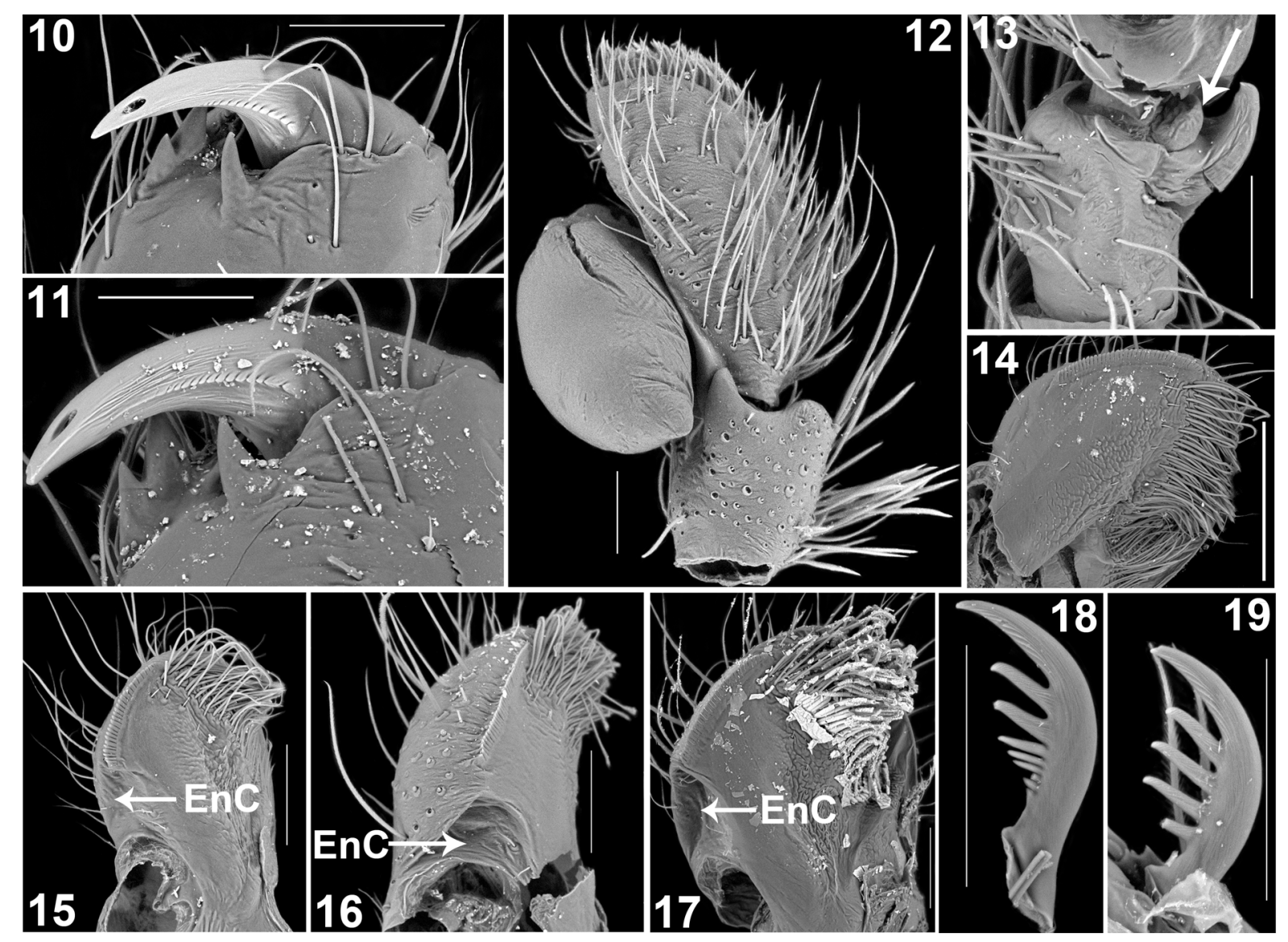

Figs 10-19. Scanning electron micrographs of Manzuma jocquei (Azarkina, Wesołowska \& RussellSmith, 2011) (10-15, 18-19), Stenaelurillus guttiger (Simon, 1901) (16) and Aelurillus v-insignitus (Clerck, 1757) (17). 10. Male left chelicerae, retromarginal view. 11. Female left chelicerae, retromarginal view. 12. Male palp, ventral view. 13. Male palpal tibia, ventral view. 14-17. Right endites. 14. Female. 15-17. Males, M. jocquei, S. guttiger and A. v-insignitus correspondingly. 18-19. Tarsal claw of legs I in males. 18. Prolateral. 19. Retrolateral. Scale bars: $0.1 \mathrm{~mm}$. 


\section{Definition}

Small spiders, ranging in body length from 2.80 to $3.75 \mathrm{~mm}$ in males and 3.80 to $4.60 \mathrm{~mm}$ in females. Sexes similar in general body shape. Males usually smaller and brighter coloured.

CARAPACE. Rather high, highest point located in PLE or just behind PLE. Colour pattern of both sexes usually with two longitudinal stripes running along the ALE-PLE lines (poorly visible or invisible in

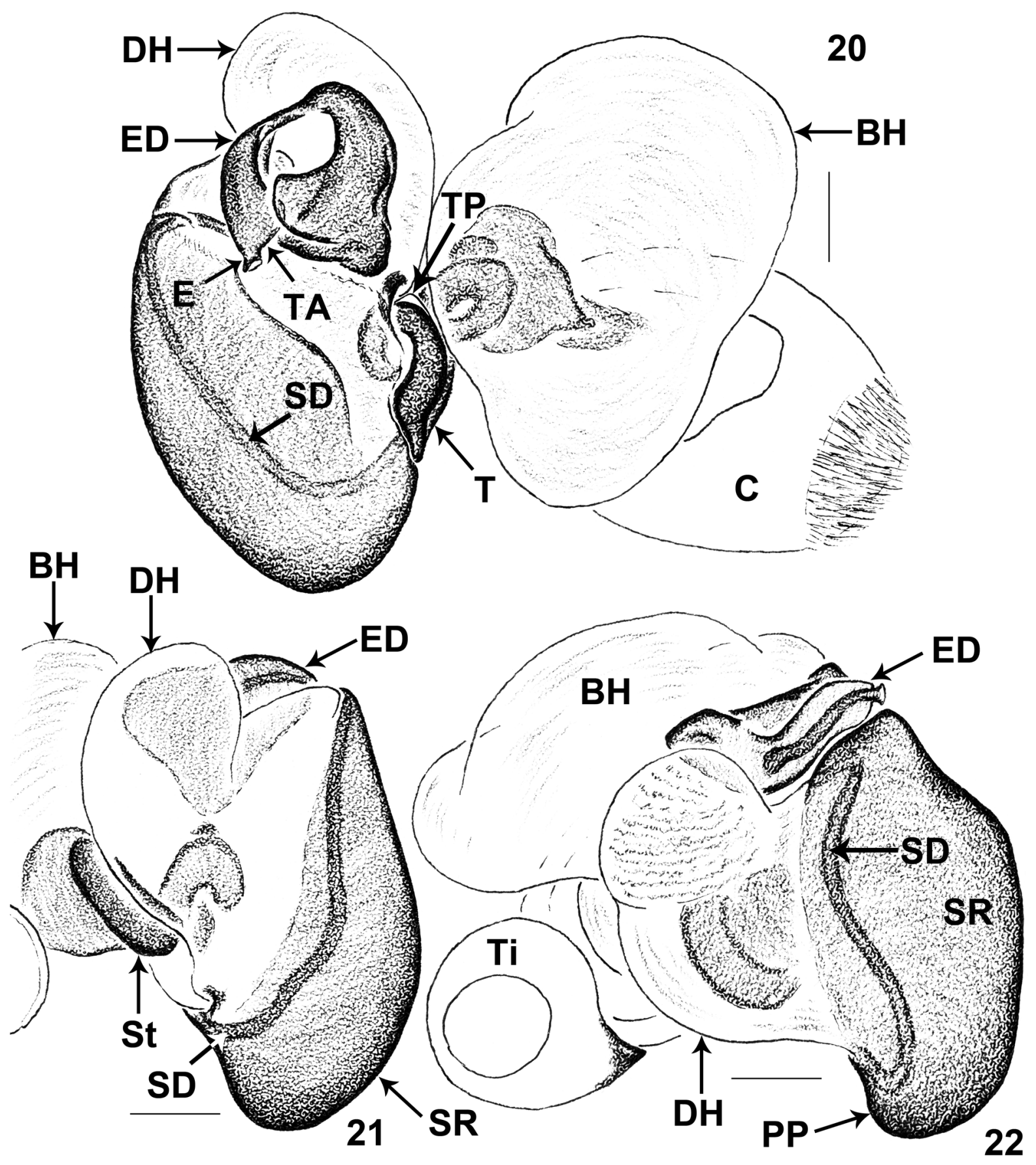

Figs 20-22. Expanded male palp of Manzuma petroae gen. et sp. nov., from South Africa (Roodeport). 20. Retrolatero-apical view. 21. Prolateral view. 22. Prolatero-apical view. Scale bars: $0.1 \mathrm{~mm}$. 
some females); fovea present and situated between PLEs; the anterior part of the eye field is covered with short erect bristles similar to the 'rod-hairs' described for Asianellus Logunov \& Heçiak, 1996 (see Logunov \& Heçiak 1996: figs 14-16).

CLYPeus. Medium to high, ranging between $50-83 \%$ of the AME diameter in males and $44-63 \%$ in females.

Chelicerae. Medium length, vertical and of usual shape; promargin with two small teeth, basally fused together, retromargin with one tooth (Figs 10-11).

ENDITES. Subparallel, of usual shape, with pale yellow to white apices; in males of all species with small retrolateral "cavity" (EnC) at the base of endites (Fig. 15), while in females this character is absent (Fig. 14).

STERnUM. Ovoid, longer than wide.

Pedicel. Short, in live specimens not visible in dorsal view (Figs 46, 50, 182-183).

ABDOMEN. Elongate, without scutum; colour markings simple - with white median longitudinal stripe in males (Figs 37, 46, 72-73, 95-96, 117-119, 143-144, 168-169, 182-183, 185, 194) and usually with two median longitudinal lines of white spots in females (Figs 42, 50, 79, 103, 150, 178).

BOOK-LUNG COVERS. Not sclerotized.

SPINNERETS. Medium in size.

LEGS. Subequal in length, with femora of legs III longer than others; female metatarsi I without retrolateral spines; in four species (M. jocquei, M. kenyaensis, M. nigritibia and M. petroae gen. et sp. nov.) femora I of male with long white or yellow-white hairs prolaterally; tarsal claws narrow, on legs I-II of male with 7-8 teeth prolaterally and 4-5 retrolaterally (Figs 18-19), on legs I-II of female with 1 or 3-4 small teeth pro- and retrolaterally. Leg formula: III/IV/II/I or III/IV/I/II in both sexes.

Female PaLP. General form, without an apical claw.

MALE PALP. Femora of usual form, densely covered with long white hairs; tibia short, with ventral short membranous apophysis (Fig. 13, arrowed) and a well-developed sclerotized ventral apophysis and bulgelike dorsal apophysis (Figs 12, 28, 61, 84, 108, 132, 155, 189), in M. kenyaensis gen. et comb. nov. with dorsal bulge (Fig. 84). Cymbium oval, without apical claw; cymbial apex densely covered with short erect hairs and poorly-marked ventral groove. Basal haematodocha is well-developed (Figs 20-22, BH) and subtegulum is simple, visible in an expanded palp only (Figs 21, 54, ST). Tegulum is narrow and elongated, with small apical tegular projection (Fig. 20, TP), in M. lympha and M. nigritibia poorly visible. The distal haematodocha is well-developed (Figs 20-22, DH) and the salticid radix has a small and rounded proximal projection (Figs 22, 52, 54, PP). Sperm duct runs from the subtegulum, down to the tegulum, and around the salticid radix in a clockwise direction to the ED (Figs 20-22, SD). The embolic division consists of the embolus with a large embolic base bearing an apical projection (Figs 20, 52, 54-55, ED, E and ApP) and a broad membranous paddle-shaped terminal apophysis curved inside, situated in both pro- and retrolateral sides of the embolus (Figs 56-59). Embolus slightly curved retrolaterally, apex broad, apically with a short membranous process (Figs 53-54). For an explanation of the male palpal composition see Logunov \& Azarkina (2018). For an explanation of the embolic division and its complex origin see Logunov (1996b), Azarkina (2002) and Azarkina \& Zamani (2019); in the latter paper EO refers to the ED in this paper. 
FEMALE COPULATORY ORGans. The epigyne has a small epigynal depression around the copulatory openings. The epigynal pocket is situated at the edge of epigastric furrow, deep, protruding ventrally, with cavity inside (Fig. 166) but epigynal wings are absent (Figs 34, 69-71, 90-91, 93, 113, 140141, 161-163). The introductory part of insemination ducts is weakly sclerotized, fused around the copulatory openings to a small tube and then bifurcated (Figs 36, 67, 94, 115, 142, 164, ID). The remaining parts of insemination ducts are heavily sclerotized, complex and consist of two multichamber sections (Figs 35, 68, 89, 114, 141, 167). The accessory glands are short (contra Wesołowska \& van Harten 1994), weakly sclerotized and in most cases seen only from an apical view or through the epigynal tegument (Fig. 164, AG). Fertilization ducts arise anteriorly at the top of spermathecae, near the copulatory openings (Fig. 164, FD).

\section{Composition}

Manzuma gen. nov. consists of seven species known from both sexes, except for M. tanzanica gen. et sp. nov. known from the male only. It includes $M$. botswana gen. et sp. nov. ( $\hat{O}$, , from Botswana and Republic of South Africa), M. jocquei gen. et comb. nov. ( $\hat{0}$, , from Ivory Coast, Nigeria and Central African Republic), M. kenyaensis gen. et comb. nov. ( $\lesssim$, , from Kenya), M. lympha gen. et comb. nov. ( $\hat{\jmath}+$, from Kenya), M. nigritibia gen. et comb. nov. ( $\hat{\alpha}+$, from Ethiopia and Yemen), M. petroae gen. et sp. nov. ( $\bigcirc+$, from Republic of South Africa), and M. tanzanica gen. et sp. nov. ( $\hat{0}$, from Tanzania).

\section{Distribution}

Afrotropical Region (sensu Dippenaar-Schoeman \& Jocqué 1997) (Fig. 200).

\section{Natural history}

Like other members of the Aelurillina (Prószyński 2017; Logunov \& Azarkina 2018), members of Manzuma gen. nov. are ground-dwellers, occurring in different biotopes with high insulation.

\section{Remarks}

Females of six Manzuma gen. nov. species show close similarity in coloration and great intraspecific variability in the structure of copulatory organs (Figs 69-71, 90-91, 113, 140, 161-163) and are almost

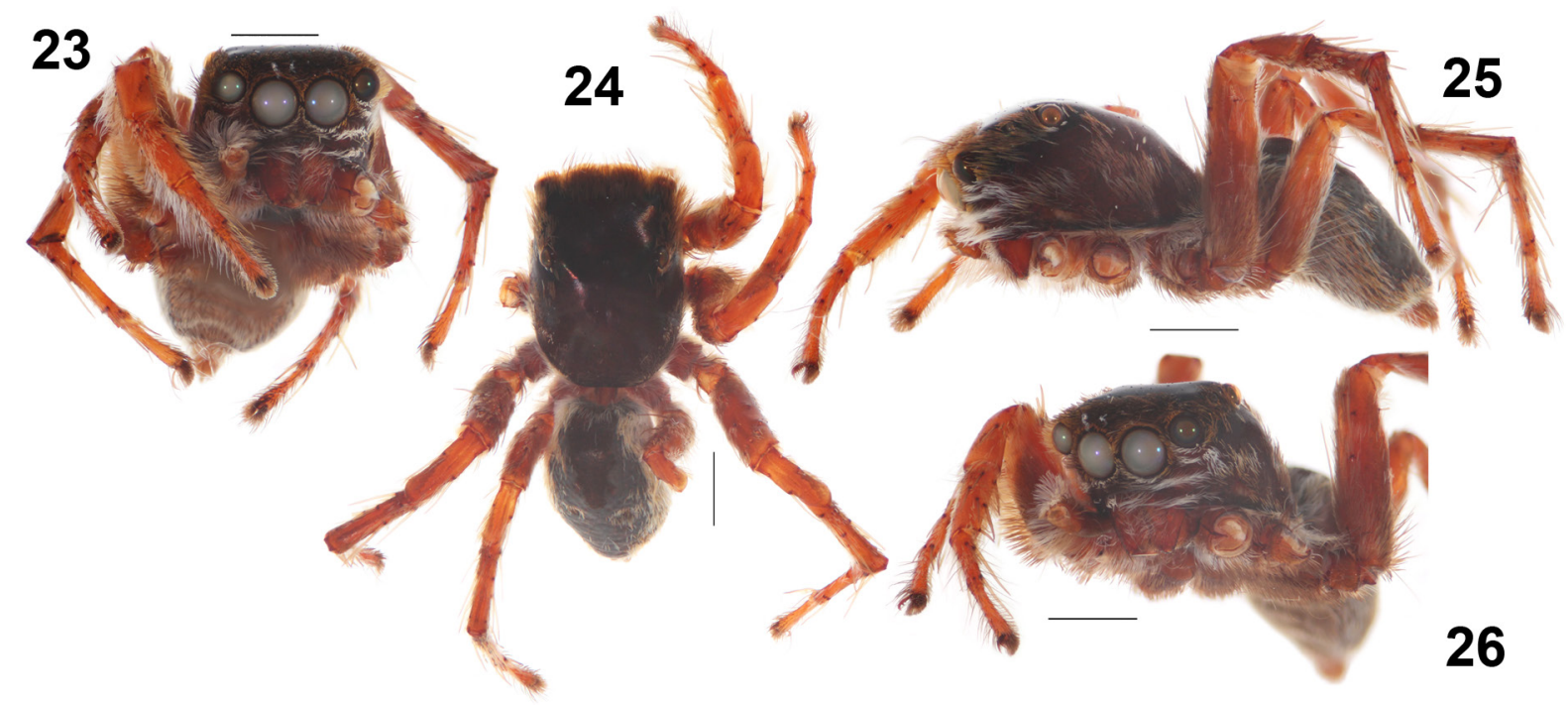

Figs 23-26. Rafalus christophori Prószyński, 1999, holotype, ô, general appearance. Scale bars: $1 \mathrm{~mm}$. 
indistinguishable from each other. Females of M. botswana gen. et sp. nov., M. kenyaensis gen. et comb. nov. and M. petroae gen. et sp. nov. have a short white stripe on the eye field just behind the AMEs and cheeks with two narrow lines of whitish dense scales running from AMEs to the sides of the carapace (Figs 42, 45, 49-50, 103, 106). Females of M. jocquei, M. lympha and M. nigritibia are almost indistinguishable except that $M$. jocquei and $M$. lympha have the cephalic part of the carapace slightly narrower, than that of M. nigritibia. Females of M. kenyaensis are most distinguishable from other species in structure of spermathecae, they have very long introductory parts of the insemination ducts, almost two-three times longer compare to other species (Figs 90-91, 93). For these reasons I was unable to produce a useable key to females.

\section{Key to species (males)}

1. Eye field with median short longitudinal stripe behind AMEs (Figs 37-39, 46, 48, 168-171, 176 177, 182-183)

- Central area of eye field covered with brown short scales, without such a stripe (Figs 72-73, 75-77, 95-96, 99-102, 117-119, 121-125, 143-145, 147-148, 194, 196-199)

2. Clypeus covered with short brown scales, with central transverse stripe of white hairs (Figs 38-39, 48). Cheeks with two stripes of white scales running from ALEs to the lateral sides of carapace (Fig. 38). Fm I prolaterally without dense long yellow-white hairs ..... M. botswana gen. et sp. nov.

- Clypeus and cheeks covered with long white hairs; clypeus with diamond-shaped patch of brown hairs between AME and on upper half of clypeus (Figs 170-171, 176-177, 186-187). Fm I prolaterally with dense long yellow-white hairs

M. petroae gen. et sp. nov.

3. Clypeus covered with sparse long brownish-white hairs (Figs 99-102). Palpal patella brown or brownish yellow dorsally, flattened, without hairs, iridescent (Figs 100-102). Palpal tibia with dorsal bulge (Fig. 84) ..M. kenyaensis (Dawidowicz \& et Wesołowska, 2016) gen. et comb. nov.

- Without these characters 4

4. Clypeus densely covered with long white hairs, without diamond-shaped patch of brown hairs between AMEs; upper half of cheeks under ALEs covered with short brown scales, basal half covered with long white hairs (Figs 75-77, 121-125, 196-197)

- Clypeus with diamond-shaped patch of brown hairs between AME and on upper half of clypeus; cheeks covered with long white hairs from ALEs to margin of carapace (Figs 145, 147-148)

M. nigritibia (Caporiacco, 1941) gen. et comb. nov.

5. TA with well developed ApP (Figs 62, 64, 111); T with poorly visible TP (Figs 61, 64, 108, 111) ...

- TA with poorly developed ApP (Fig 192); T with clearly visible TP (Figs 189, 192). Ts, Mt and Ti I ventrally not dark brown (Figs 195, 197-199) M. tanzanica gen. et sp. nov.

6. Ts, Mt and Ti I ventrally brown or dark brown (Figs 74-78); tip of ApP pointed dorsally (Fig. 64); tibial apophysis broad (Fig. 61)

M. jocquei (Azarkina, Wesołowska \& Russell-Smith, 2011) gen. et comb. nov.

- Ts, Mt and Ti I ventrally yellow or brownish (Figs 116, 120-122); tip of ApP ponted ventrally (Fig. 111); tibial apophysis narrow (Fig. 108)

M. lympha (Próchniewicz \& Heçiak, 1994) gen. et comb. nov. 


\section{Manzuma botswana gen. et sp. nov. urn:lsid:zoobank.org:act:63B5C104-A877-448E-804A-36966BDAB2FC}

Figs $27-48,200$

\section{Diagnosis}

Manzuma botswana gen. et sp. nov. is most similar to M. petroae gen. et sp. nov. in body coloration. The males of M. botswana gen. et sp. nov. differ in having the clypeus covered with short brown scales, medially with a thin vertical stripe of white hairs (Figs 39, 48), while in M. petroae gen. et sp. nov. the clypeus is covered with long white hairs with a diamond-shaped patch of brown hairs between AME and on upper half of clypeus in the center (Figs 170-173, 176-177, 186-187). The cheeks in M. botswana gen. et sp. nov. have a thin white line running from ALEs to the sides of the carapace (Fig. 38), while in M. petroae gen. et sp. nov. the cheeks are covered with yellowish-white hairs (Figs 171, 177). Apical projection (ApP) in M. botswana gen. et sp. nov. is large and robust (Fig. 31), while ApP in M. petroae gen. et sp. nov. is smaller in size, rounded in lines and slightly bent dorsally (Fig. 158). The females of $M$. botswana gen. et sp. nov. differ in having a short narrow white stripe on the eye field just behind the AMEs (Figs 42, 44), while females of M. petroae gen. et sp. nov. have short wide stripe (Figs 49-51), almost invisible in specimens preserved in alcohol (Figs 178, 180).

\section{Etymology}

The species epithet is a noun in apposition taken from the country of the type locality, Botswana.

\section{Material examined}

\section{Holotype}

BOTSWANA • ${ }^{\wedge}$; North-West/Ngamiland District, Okavango Delta, Maxwee; $19.4667^{\circ} \mathrm{S}, 23.6500^{\circ} \mathrm{E}$; May-Sep. 1976; A. Russell-Smith leg.; floodplain, grassland; MRAC.

\section{Paratypes}

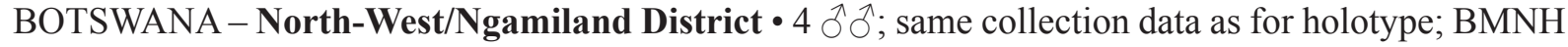

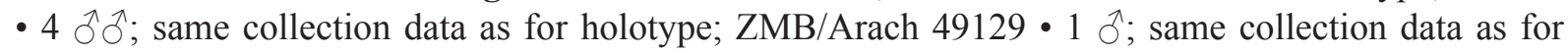

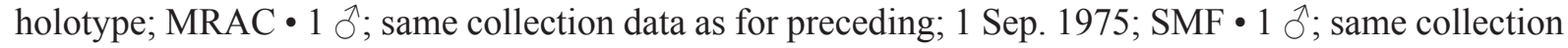
data as for preceding; 28 Nov. 1975; MHNG $\bullet 1$ 今 ; same collection data as for preceding; 2 Jan. 1976;

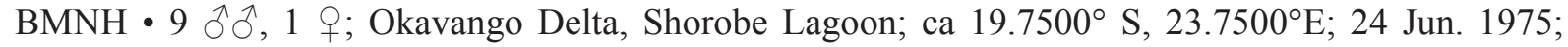
A. Russell-Smith leg.; grassland; pitfall traps; BMNH $\bullet 3$ ते $\delta^{\lambda}$; same collection data as for preceding;

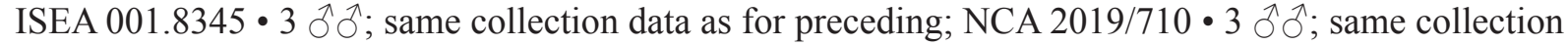
data as for preceding; MMUE G7631.1 • 1 q; Moremi Game Reserve, Mboma Lagoon; ca $19.1833^{\circ}$ S, 23.2667 E; 13 Aug. 1977; A. Russell-Smith leg.; in Hyparrhenia grassland; MRAC • 1 \%; Crocodile Camp; ca $19.9167^{\circ} \mathrm{S}, 23.5000^{\circ}$ E; 25 Jun. 1979; B. Taylor and A. Morely leg.; NCA 83/494.

SOUTH AFRICA 1 ○ ; Limpopo Province, Lekgalameetse Reserve; ca $24.1833^{\circ}$ S, $30.1833^{\circ}$ E; 25 Sep. 2015; P. \& L. Webb leg.; NCA 2019/711.

\section{Description}

Male (the smallest holotype MRAC, the biggest NCA 2019/711)

Measurements: carapace: $1.70-1.90$ long, $1.45-1.50$ wide, 1.10 high. Abdomen: $1.70-1.75$ long, $1.35-$ 1.50 wide. Ocular area: $0.80-0.85$ long, $1.15-1.20$ wide anteriorly, $1.10-1.15$ wide posteriorly. Cheliceral length $0.55-0.60$. Clypeal height 0.25. Diameter of AME 0.30-0.35. Length of leg segments (bigger NCA 2019/711): I $1.00+0.65+0.70+0.55+0.50(3.40) ;$ II $1.05+0.65+0.65+0.55+0.45$ (3.35); III $1.50+0.80+0.95+1.00+0.50(4.75) ;$ IV $1.30+0.60+0.85+1.00+0.50(4.25)$. Leg spination: I: Fm d 0-1-1-5; Pt pr and rt 1; Tb d 1-0-0, pr 1-1-1, rt 1-1-0, v 2-2-2 ap; Mt pr and rt 1-1 ap, v 2-2 ap. II: Fm 


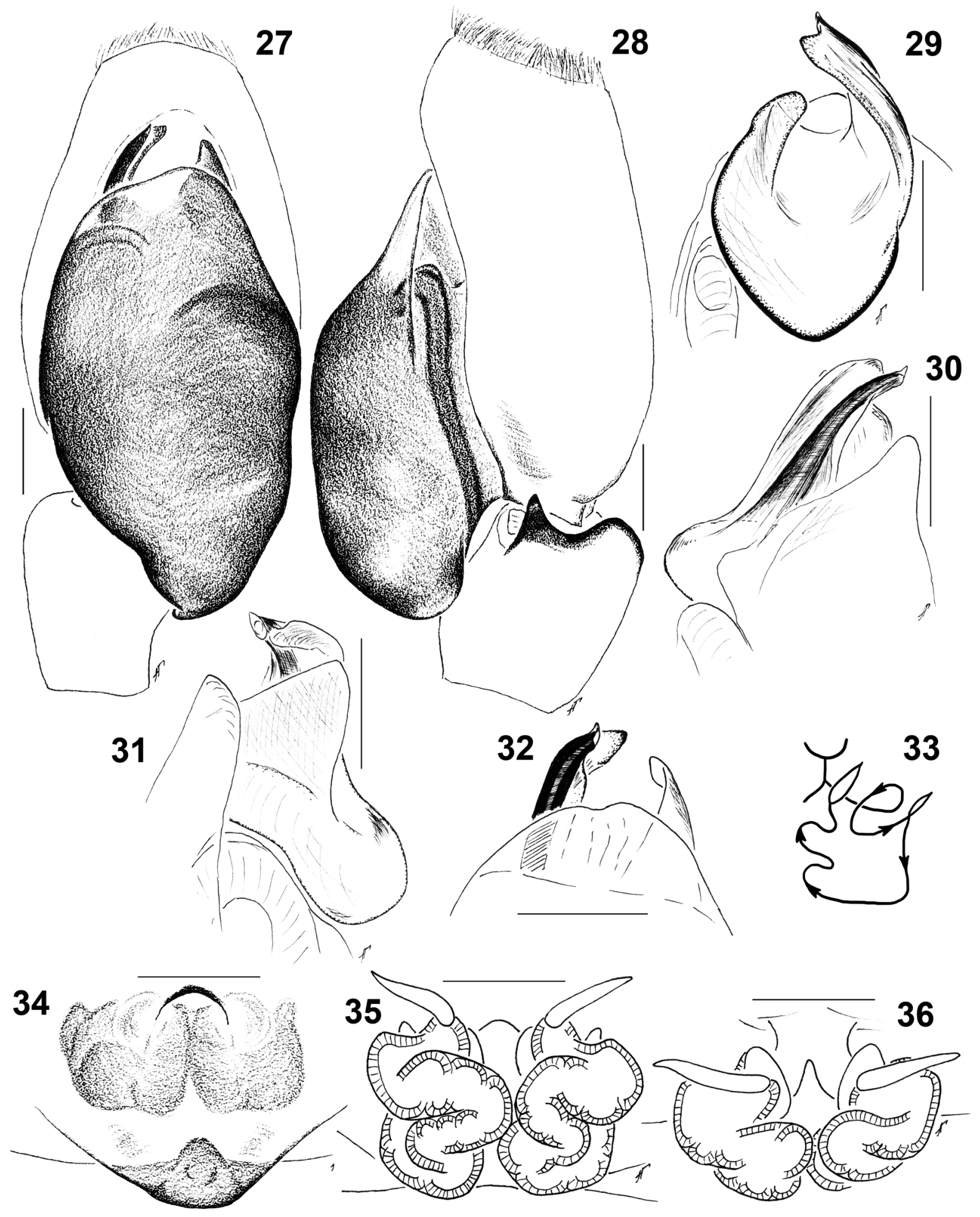

Figs. 27-36. Manzuma botswana gen. et sp. nov., holotype, $\widehat{\partial}(27-28)$, paratype, $\widehat{\jmath}$ from Maxwee (2932), paratype,, from Shorobe Lagoon (33-36). 27-28. Male palp. 27. Ventral view. 28. Retrolateral view. 29-32. Embolic division. 29. Dorsal view. 30. Prolateral view. 31. Retrolateral view. 32. Ventral view. 33. Diagrammatic course of the insemination ducts. 34. Epigyne, ventral view. 35-36. Spermathecae. 35. Dorsal view. 36. Apical view. Scale bars: $0.1 \mathrm{~mm}$. 


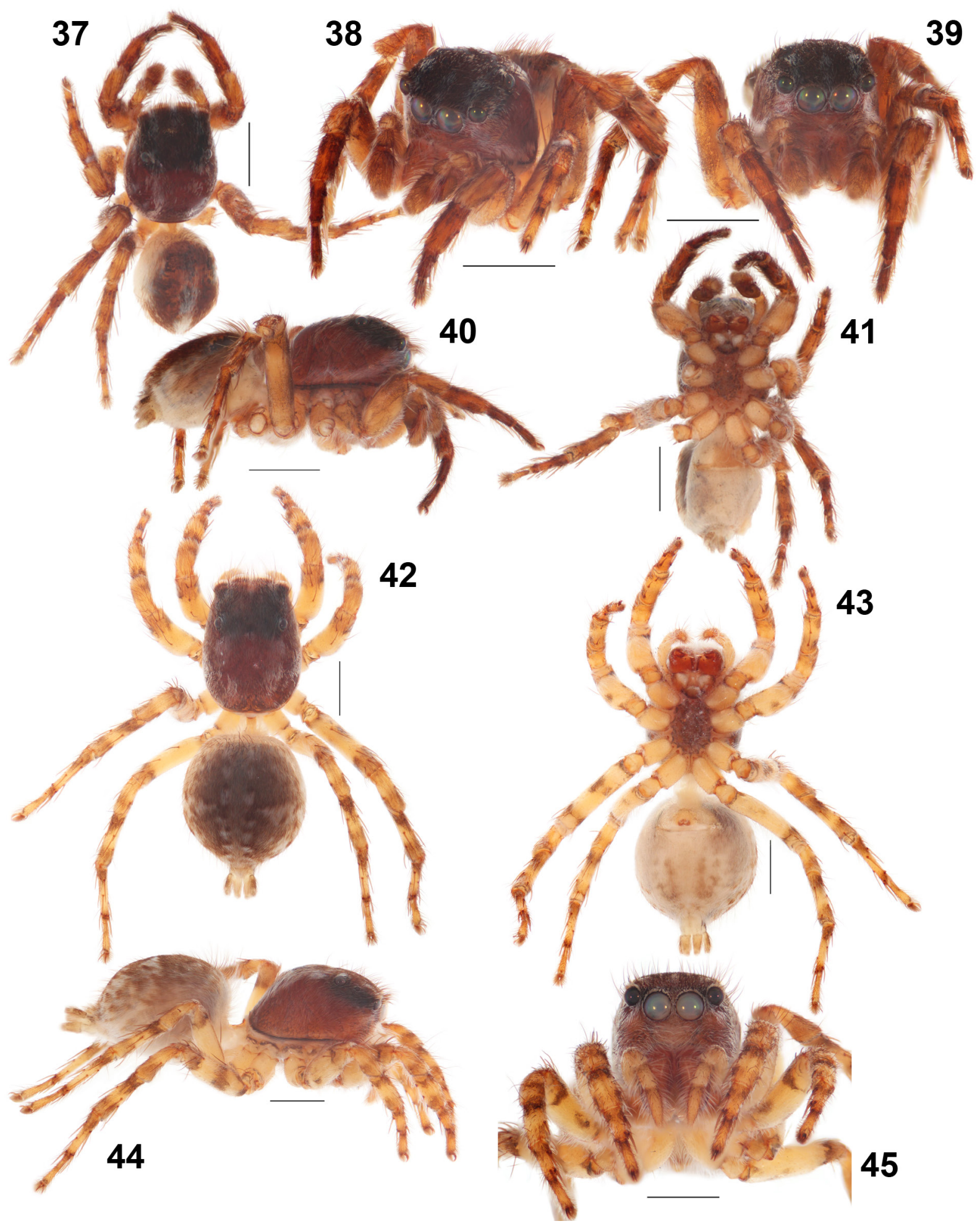

Figs 37-45. Manzuma botswana gen. et sp. nov., holotype, $\widehat{\partial}(37-41)$ and paratype, $\varnothing$ from Moremi GR (42-45), general appearance. Scale bars: $1 \mathrm{~mm}$. 

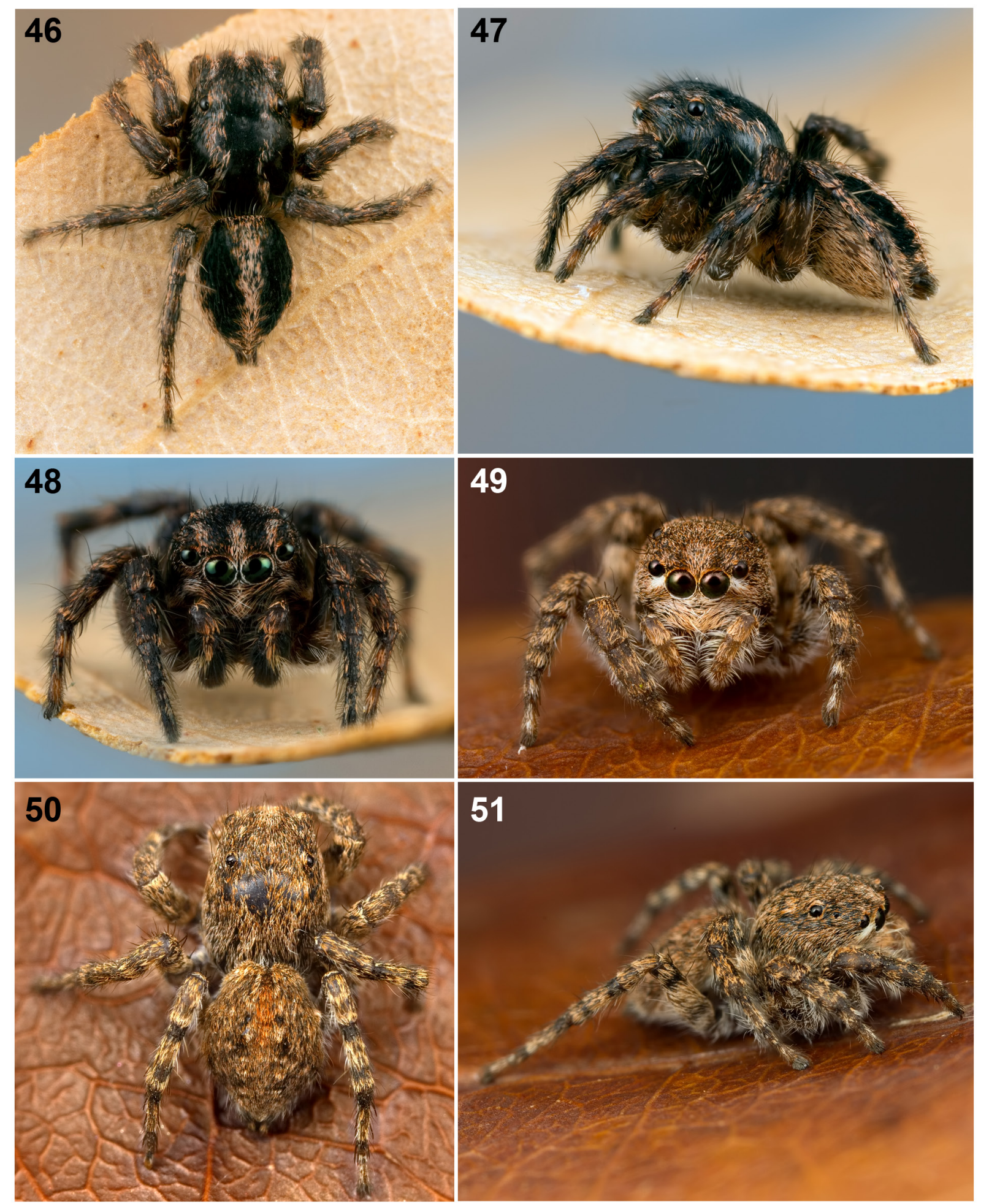

Figs 46-51. 46-48. Manzuma botswana gen. et sp. nov., general appearance of live $\widehat{\partial}$ from South Africa. 49-51. Manzuma petroae gen. and sp. nov., general appearance of live $\odot$ from South Africa, photos (C) Vida van der Walt. 
d 0-1-3-5; Pt pr and rt 1; Tb d 1-0-0; pr 1-1-1, rt 1-1-0; v 1-1-2 ap; Mt pr and rt 1-1ap, 2-2 ap. III: Fm d 0-1-3-5; Pt pr and rt 1; Tb d 1-0-0, pr 1-1-1-1, rt 1-1-1-0, v 1-0-2 ap; Mt d 1-1-0, pr and rt 1-0-2 ap, v 2-0-2 ap. IV: Fm d 0-1-2-5; Pt pr and rt 1; Tb d 1-0-0, pr and rt 1-1-1-1, v 1-0-2 ap; Mt d 1-1-0, pr 1-1-2 ap, rt 1-0-2 ap, v 2-0-2 ap. Coloration (in alcohol: Figs 37-41; live specimens: 46-48). Carapace brown, eye field dark brown, covered with short brown scales, with two longitudinal stripes of white scales running from ALEs to the rear end, sides covered with white thin stripe of scales. Eye field with short white longitudinal stripe of white scales running from AMEs to $1 / 2$ length of eye field. Sternum yellowbrown to brown. Endites and labium brown-yellow. Chelicerae yellow-brown. Clypeus yellow-brown to brown, with central transverse stripe of white hairs. Cheeks brown, with two stripes of white scales running from ALEs to the lateral sides of carapace. Abdomen: dorsum brown, medially with longitudinal white stripe; venter brownish yellow. Book-lungs covers yellow. Spinnerets: anterior brownish yellow, posterior brown. All legs yellowish-brown. Femora of all legs apically brown. Patellae I ventrally brown. Tibiae, metatarsi and tarsi I prolaterally and ventrally dark brown. Palps brown-yellow. Palpal femora retrolatrally covered with short dark-brown hairs, ventrally and prolatero-apically densely covered with with white hairs. Tibia and cymbium covered with brown hairs, retrolaterally with white hairs. Palpal structure as in Figs 27-32: tegulum with clearly visible proximal projection; apical projection large; TA apically pointed.

Female (BMNH and MRAC)

Measurements: carapace: 2.15 long, 1.45 wide, 1.20 high. Abdomen: damaged and cannot be measured. Ocular area: 1.00 long, 1.35 wide anteriorly, 1.30 wide posteriorly. Cheliceral length 0.75 . Clypeal height 0.25. Diameter of AME 0.40. Length of leg segments: I $1.10+0.70+0.80+0.50+0.50(3.60)$; II $1.10+0.70+0.70+0.50+0.45(3.45)$; III $1.80+0.90+1.00+0.90+0.70(5.30) ;$ IV $1.50+0.70+$ $1.00+1.20+0.60$ (5.00). Leg spination: I: Fm d 0-1-1-4; Tb pr 1-1, v 2-2-2 ap; Mt pr 1-1 ap, v 2-2 ap. II: Fm d 0-1-1-4; Tb pr 1-1, v 1-1-2 ap; Mt pr 1-1 ap, v 2-2 ap. III: Fm d 0-1-2-4; Pt pr and rt 1; Tb d 1-0-0, pr and rt 1-1-1, v 1-0-2 ap; Mt d 1-1-0, pr and rt 1-0-2 ap, v 1-1-2 ap. IV: Fm d 0-1-1-2; Pt pr and rt 1; Tb d 1-0-0, pr and rt 1-1-1, v 1-0-2 ap; Mt d 1-1-0, pr 1-1-2 ap, rt 1-0-2 ap, v 1-1-2 ap. Coloration (in alcohol: Figs 42-45). Coloration similar to that of males. Clypeus whithout medial thin white stripe. Cheeks with white stripes of scales running from outer rim of AME's to lateral sides of carapace. All legs brownish yellow. Abdomen: dorsum brown, medially with two longitudinal rows of white dots. Spinnerets brownish yellow. Epigyne and spermathecae as in Figs 33-36: copulatory openings almost invisible; epigynal pocket low, central structure is $1 / 3$ of epigynal hight; inferior border of EP convex caudally.

\section{Distribution}

Botswana, South Africa (Fig. 200).

Manzuma jocquei (Azarkina, Wesołowska \& Russell-Smith, 2011) gen. et comb. nov.

Figs 10-15, 18-19, 52-82, 200

Aelurillus jocquei Azarkina, Wesołowska \& Russell-Smith, 2011 in Wesołowska \& Russell-Smith, 2011: 557, figs 7-13, 215-216; 9 holotype from BMNH, not examined.

\section{Diagnosis}

Manzuma jocquei is most similar in body coloration to M. lympha, M. nigritibia and M. tanzanica. The males can be distinguished from M. tanzanica by the well developed apical projection (ApP) (poorly developed in M. tanzanica) (cf. Figs 57-58, 64 and 190, 192 correspondingly). From M. lympha is can be distinguished by more robust ApP pointed dorsally in M. jocquei (Figs 55, 64) while in M. lympha ApP smaller in size and pointed ventrally (Fig. 111). From M. nigritibia it can be distinguished by the 
coloration of the clypeus and cheeks. The upper half of the cheeks under ALEs are covered with short brown scales and the basal half of the cheeks are covered with long white hairs (Figs 75-77) while in M. nigritibia the clypeus has a diamond-shaped patch of brown hairs between AME and on the upper half of clypeus, the cheeks are covered with long white hairs from ALEs to margin of carapace (Figs 145, 147). The females cannot be distinguished from M. lympha and M. nigritibia but can be distinguished from M. botswana gen. et sp. nov. and M. petroae gen. et sp. nov. by the absence of white stripes of scales running from the outer rim of AME's to the lateral sides of carapace (cf. Figs 82, 129, 152,44 and 180 correspondingly).

\section{Material examined}

CENTRAL AFRICAN REPUBLIC • 1 क; Bambari; ca 5.7500 N, 20.6667 E, Aug.-Sep. 1967; G. Pierrard leg.; MRAC 133.906.

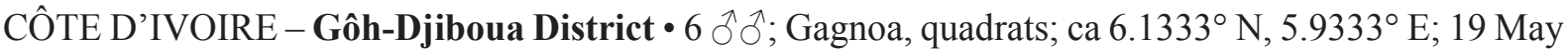

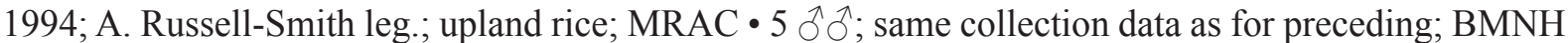

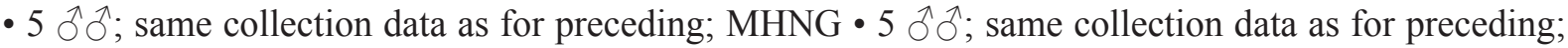
$\mathrm{SMF} \cdot 5$ ồ; same collection data as for preceding; $\mathrm{ZMB} /$ Arach 49128. - Vallée du Bandama District

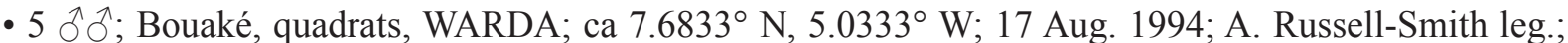

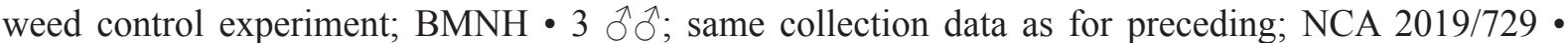
$6 \widehat{\partial}$; same collection data as for preceding; ISEA 001.8351・1 $\hat{\jmath}, 3$ 오; same collection data as for preceding; ISEA 001.8352 • $5 \widehat{\partial} \widehat{\jmath}$; same collection data as for preceding; MMUE G7631.2 $\bullet 5 \hat{\jmath}$, 2 오; same collection data as for preceding; MMUE G7631.3 • $1 \hat{0}, 2$ 우; same collection data as for preceding; NCA 2019/730 • 2 오; same collection data as for preceding; ZMB/Arach 49130 - 1 ㅇ; same locality as for preceding; 30 Nov. 1994; A. Russell-Smith leg.; SMF. - Yamoussoukro Autonomous District • 1 \% ; Kossou; ca $7.0000^{\circ}$ N, $5.4833^{\circ}$ W; 2 Feb. 1975; R. Jocqué leg.; savanna; MRAC 152.953. - Montagnes District • $3 \partial^{\lambda}$; Man, road to Tonkoui; ca $7.4000^{\circ} \mathrm{N}, 7.5167^{\circ} \mathrm{W} ; 13$ Nov. 1975; J.-C. Ledoux leg.; degraded forest, on the ground; MNHN 1 ¿ ${ }^{\circ}$; Cavally forest, ca $6.0833^{\circ}$

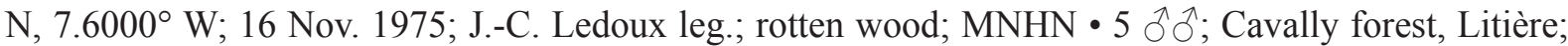
$6.0833^{\circ} \mathrm{N}, 7.6000^{\circ} \mathrm{W}, 17$ Nov. 1975; J.-C. Ledoux leg.; MNHN. - Lagunes District • 1 $\circ$; Réserve naturelle scientifique de Lamto; ca $6.2167^{\circ} \mathrm{N}, 5.0333^{\circ} \mathrm{W} ; 23$ Oct. 1975; J.-C. Ledoux leg.; Loudetia savanna, on the ground; MNHN.

\section{Description}

Male (the smallest ZMB/Arach 49128, the biggest ZMB/Arach 49128)

Measurements: carapace: $1.50-2.00$ long, $1.20-1.55$ wide, $0.85-1.10$ high. Abdomen: $1.30-1.75$ long, $1.00-1.30$ wide. Ocular area: $0.70-0.90$ long, $1.05-1.20$ wide anteriorly, $1.00-1.15$ wide posteriorly. Cheliceral length $0.50-0.60$. Clypeal height $0.15-0.25$. Diameter of AME $0.30-0.35$. Length of leg segments: I $1.00+0.60+0.60+0.50+0.45$ (3.15); II $1.00+0.60+0.65+0.50+0.45$ (3.20); III 1.50 $+0.70+0.70+0.90+0.50(4.30)$; IV $1.30+0.60+0.70+0.90+0.55$ (4.05). Leg spination: I: Fm d $0-1-1-5$; Pt pr 1 or pt and rt 1; Tb pr 1-1-1, rt 0-1-0, v 2-2-2 ap; Mt pr and rt 1-1 ap, v 2-2 ap. II: Fm d 0-1-2-5; Pt pr 1 or pr and rt 1; Tb d 1-0-0; pr 1-1-1, rt 0-1-0; v 1-1-2 ap; Mt pr and rt 1-1ap, v 2-2 ap. III: Fm d 0-1-2-5 or 0-1-3-5; Pt pr and rt 1; Tb d 1-0-0, pr and rt 1-1-1-1, v 1-0-2 ap; Mt d 1-1-0, pr and rt 1-0-2 ap, v 2-0-2 ap. IV: Fm d 0-1-1-5; Pt pr and rt 1; Tb d 1-0-0, pr 1-1-1, rt 1-1-1-1, v 1-0-2 ap; Mt d 1-1-0, pr 1-1-2 ap, rt 1-0-2 ap, v 2-0-2 ap. Coloration (in alcohol; Figs 72-78). Carapace brown, eye field dark brown, covered with brown scales, with two longitudinal white stripes of scales running from PLEs to the rear margin of the carapace; sides covered with white stripes of scales. Sternum brown. Endites and labium yellow-brown. Chelicerae brown, covered with white hairs. Clypeus and cheeks brown, densely covered with long white hairs, upper half of cheeks under ALEs covered with short brown scales, basal half of cheeks covered with long white hairs. Abdomen: dorsum dark brown, medially with longitudinal white stripe; ventral yellow-grey. Book-lung covers yellow-grey. Spinnerets: anterior 

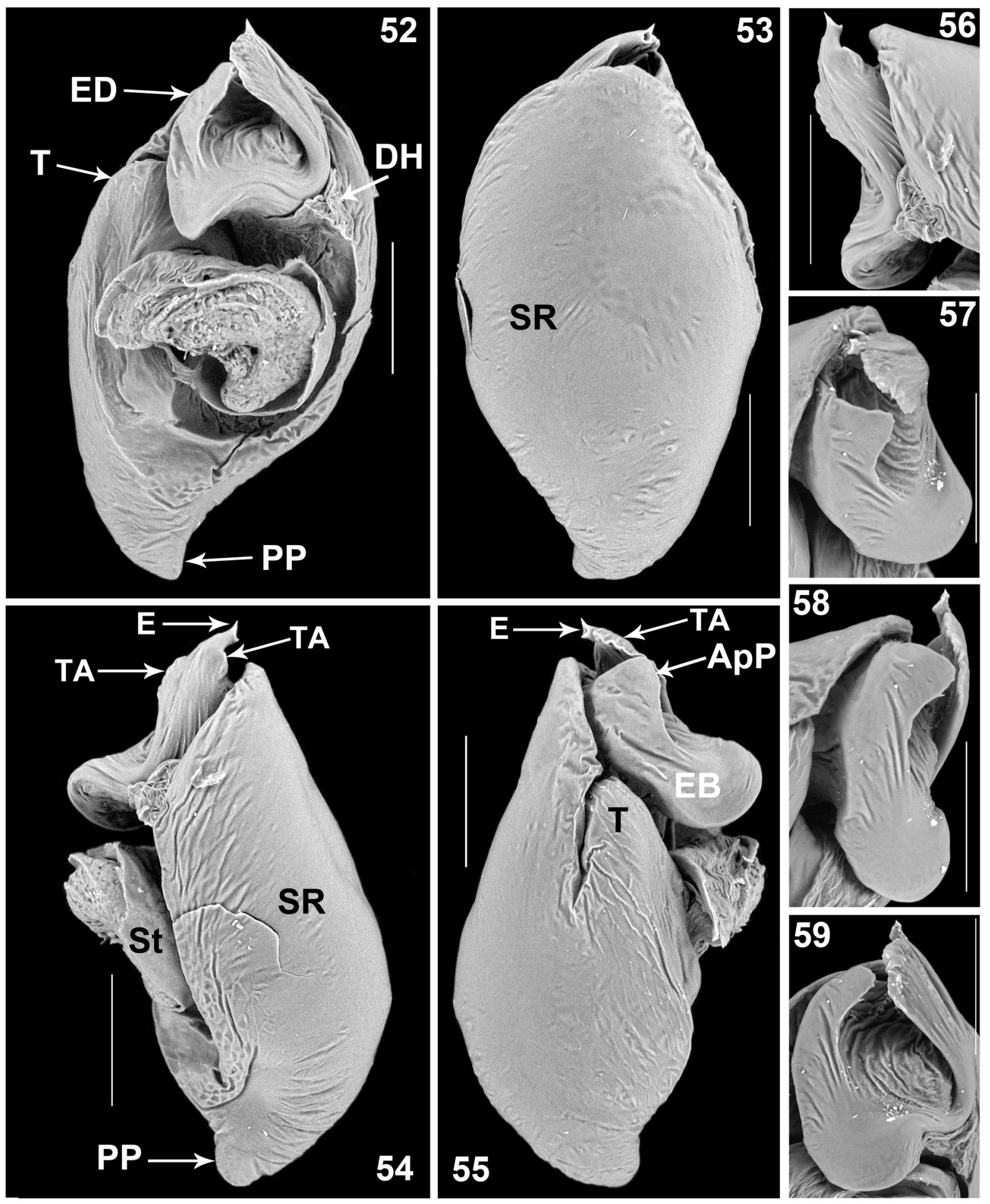

Figs 52-59. Manzuma jocquei (Azarkina, Wesołowska \& Russell-Smith, 2011) gen. et comb. nov., from Côte d'Ivoire (Gagnoa), scanning electron micrographs. 52-55. Male bulbus. 52. Dorsal view. 53. Ventral view. 54. Prolateral view. 55. Retrolateral view. 56-59. Embolic division. 56. Prolateral view. 57. Retrolatero-apical view. 58. Retrolateral view. 59. Dorsal view. Scale bars: $0.1 \mathrm{~mm}$. 


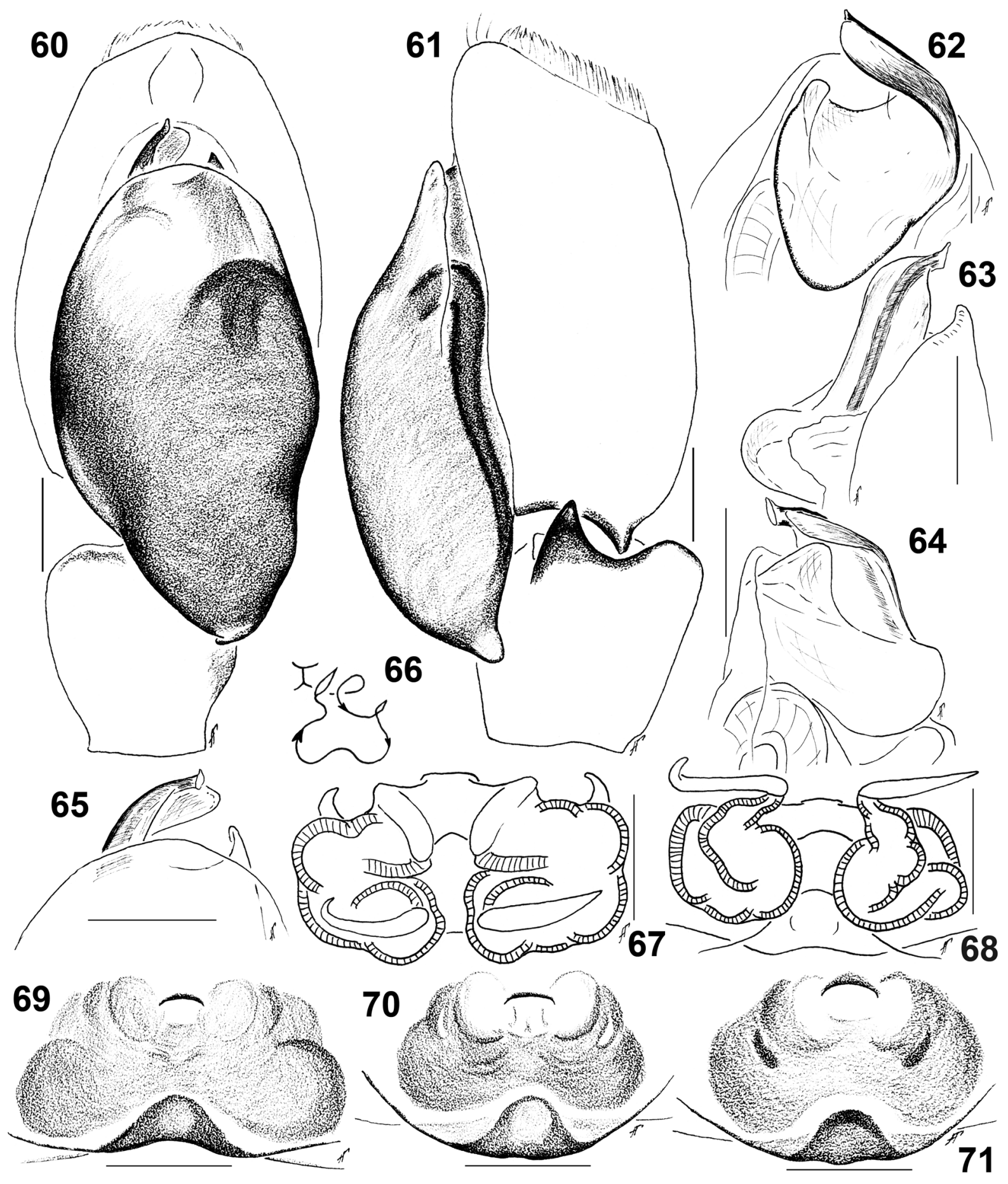

Figs 60-71. Manzuma jocquei (Azarkina, Wesołowska \& Russell-Smith, 2011) gen. et comb. nov., $\widehat{\jmath} \widehat{\partial}$ from Côte d'Ivoire (Gagnoa, ZMB/Arach 49128, SMF) (60-65), 우 from Côte d'Ivoire (Bouaké, ISEA 001.8352, NCA 2019/730) (67-70) and Central African Republic (Bambari, MRAC 133.906) (71). 60-61. Male palp. 60. Ventral view. 61. Retrolateral view. 62-65. Embolic division. 62. Dorsal view. 63. Prolateral view. 64. Retrolateral view. 65. Ventral view. 66. Diagrammatic course of the insemination ducts. 67-68. Spermathecae. 67. Apical view. 68. Dorsal view. 69-71. Epigyne, ventral view. Scale bars: $0.1 \mathrm{~mm}$. 


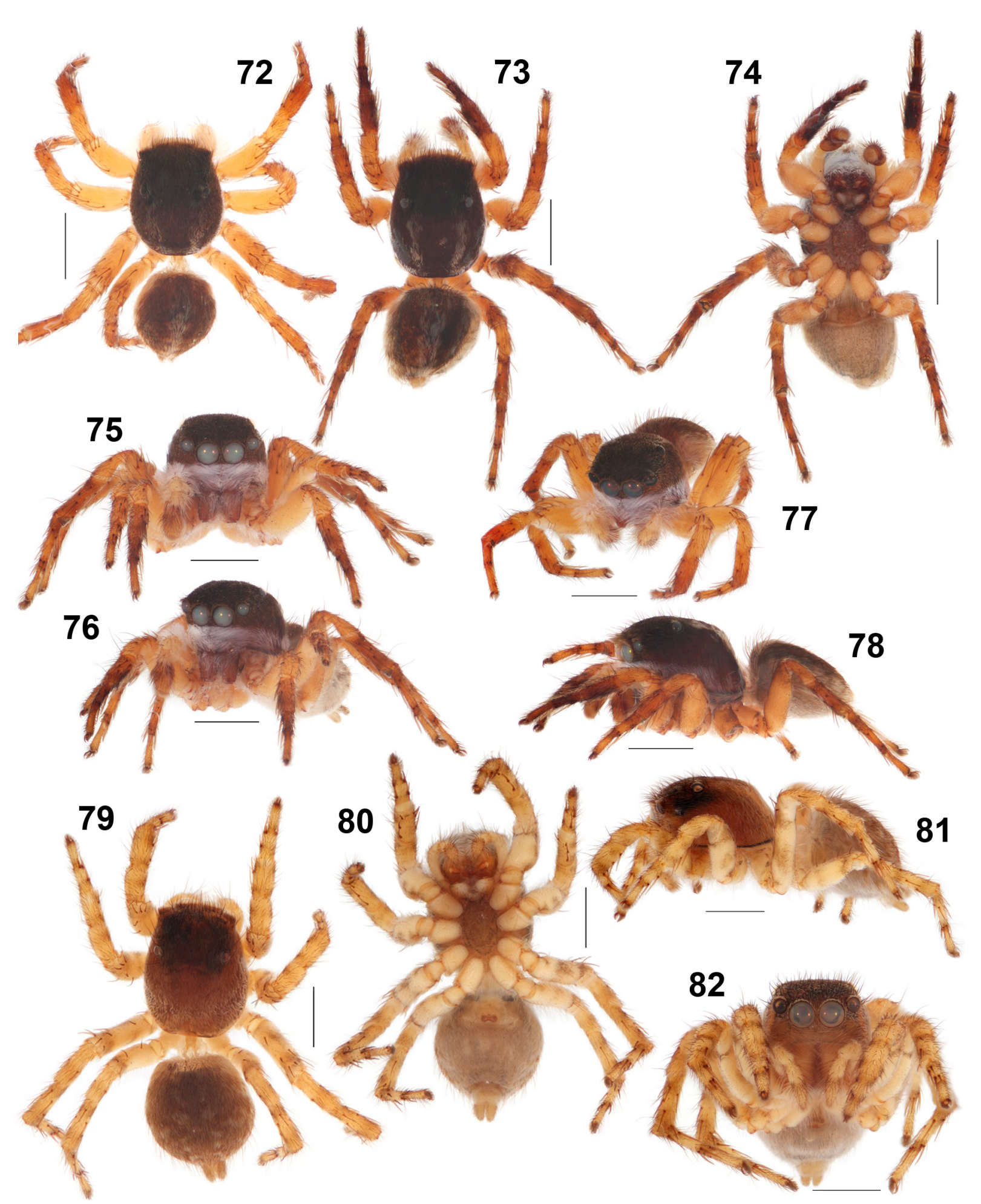

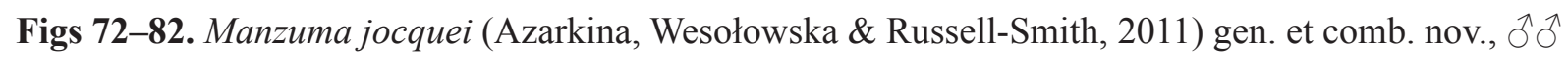
from Gagnoa (73-76, 78) and Bouaké (72, 77), ㅇ from Bouaké (79-82, NCA 2019/730), general appearance. Scale bars: $1 \mathrm{~mm}$. 
yellow, posterior brown. All legs yellow to brownish yellow. Femora I prolaterally densely covered with long white hairs. Tibiae, metatarsi and tarsi I ventrally dark-brown. Palps yellow, covered with long white hairs; cymbium brown. Palpal structure as in Figs 52-59, 60-65: tegulum with small, almost invisible proximal projection; apical projection medium in size; TA broad apically.

Female (NCA 2019/730)

Measurements: carapace: 2.10 long, 1.80 wide, 1.10 high. Abdomen: 2.30 long, 1.80 wide. Ocular area: 0.95 long, 1.40 wide anteriorly, 1.35 wide posteriorly. Cheliceral length 0.75 . Clypeal height 0.20 . Diameter of AME 0.45. Length of leg segments: I $1.10+0.70+0.70+0.45+0.40$ (3.35); II $1.00+0.60$ $+0.60+0.50+0.45(3.15) ;$ III $1.50+0.90+0.90+0.90+0.60(4.80) ;$ IV $1.30+0.80+0.80+1.00+$ 0.60 (4.50). Leg spination: I: Fm d 0-1-1-4; Tb pr 0-0 or 1-0, v 2-2-2 ap; Mt pr 1-1 ap, v 2-2 ap. II: Fm d 0-1-2-4; Tb pr 0-1 or 1-1, v 1-1-2 ap; Mt pr 1-1 ap, v 2-2 ap. III: Fm d 0-1-2-4; Pt pr and rt 1; Tb d 1-0-0, pr and rt 1-1-1, v 1-0-2 ap; Mt d 1-1-0, pr and rt 1-0-2 ap, v 2-0-2 ap. IV: Fm d 0-1-1-1 or 0-1-1-2; Pt pr and rt 1; Tb d 1-0-0, pr and rt 0-1-1 or 1-1-1, v 1-0-2 ap; Mt d 1-1-0, pr 1-1-2 ap, rt 1-0-2 ap, v 2-0-2 ap. Coloration (in alcohol; Figs 79-82). Carapace brown, eye field dark brown, covered with whitish scales, with two hardly visible longitudinal white stripes of scales. Sternum yellow-brown. Endites, labium and chelicerae brownish yellow. Clypeus and cheeks brownish yellow, covered white long hairs. Abdomen: dorsum brown, medially with two longitudinal rows of white spots; venter yellow-grey. Book-lung covers grey-yellow. Spinnerets yellow. All legs and palps yellow. All femora apically brownish. Palps yellow, palpal tibia brownish. Epigyne and spermathecae as in Figs 66-71: copulatory openings almost invisible; epigynal pocket low to medium, central structure about $1 / 3-1 / 2$ of epigynal hight.

\section{Distribution}

Côte d'Ivoire, Nigeria and Central African Republic (Fig. 200).

\section{Comments}

The female from Central African Republic is provisionally assigned to Manzuma jocquei gen. et comb. nov. This female seems to belong to another, undescribed Manzuma species occurring in Central Africa. Males collected together with the females from Central Africa are required to resolve this problem.

Manzuma kenyaensis (Dawidowicz \& Wesołowska, 2016) gen. et comb. nov. Figs 83-106, 200

Langelurillus kenyaensis Dawidowicz \& Wesołowska, 2016: 448, figs 43-44; + holotype from MEUU, not examined.

\section{Diagnosis}

The males of M. kenyaensis gen. et comb. nov. can easily be distinguished from those of all other species of Manzuma gen. nov. by dorsal bulge on palpal tibia (Fig. 84) and palpal patella brown or brownish yellow dorsally, flattened, almost without hairs, iridescent (Fig. 102). The females of M. kenyaensis gen. et comb. nov. can easily be distinguished from other Manzuma gen. nov. species by long introductory parts of the insemination ducts (Figs 90-91, 93).

\section{Material examined}

KENYA - West Pokot Country • 1 क ; Kamatira; ca $1.2500^{\circ}$ N, 35.1333 E; 2000 m a.s.1., 24 Aug. 1974; J. Murphy leg.; roadside scrub; MMUE G7572.11 • 6 ๙ $\partial^{1}, 1$ क; Kwaisagat; ca $1.2500^{\circ} \mathrm{N}, 35.1667^{\circ} \mathrm{E}$; 2400 m a.s.1.; 1 Jul. 1984; J. Murphy leg.; MMUE G7572.12, MMUE G7572.13. - Nyeri Country • 1 ô, 1 क ; Naro Moru; ca $0.1500^{\circ}$ S, 37.0166 E; 2000 m a.s.l.; 17 Aug. 1974; J. Murphy leg.; riverside scrub; ISEA 001.8307. - Trans-Nzoia Country • $1{ }^{\lambda}$; Kitale Forest; ca $1.0167^{\circ}$ N, $35.0000^{\circ}$ E; $2000 \mathrm{~m}$ 


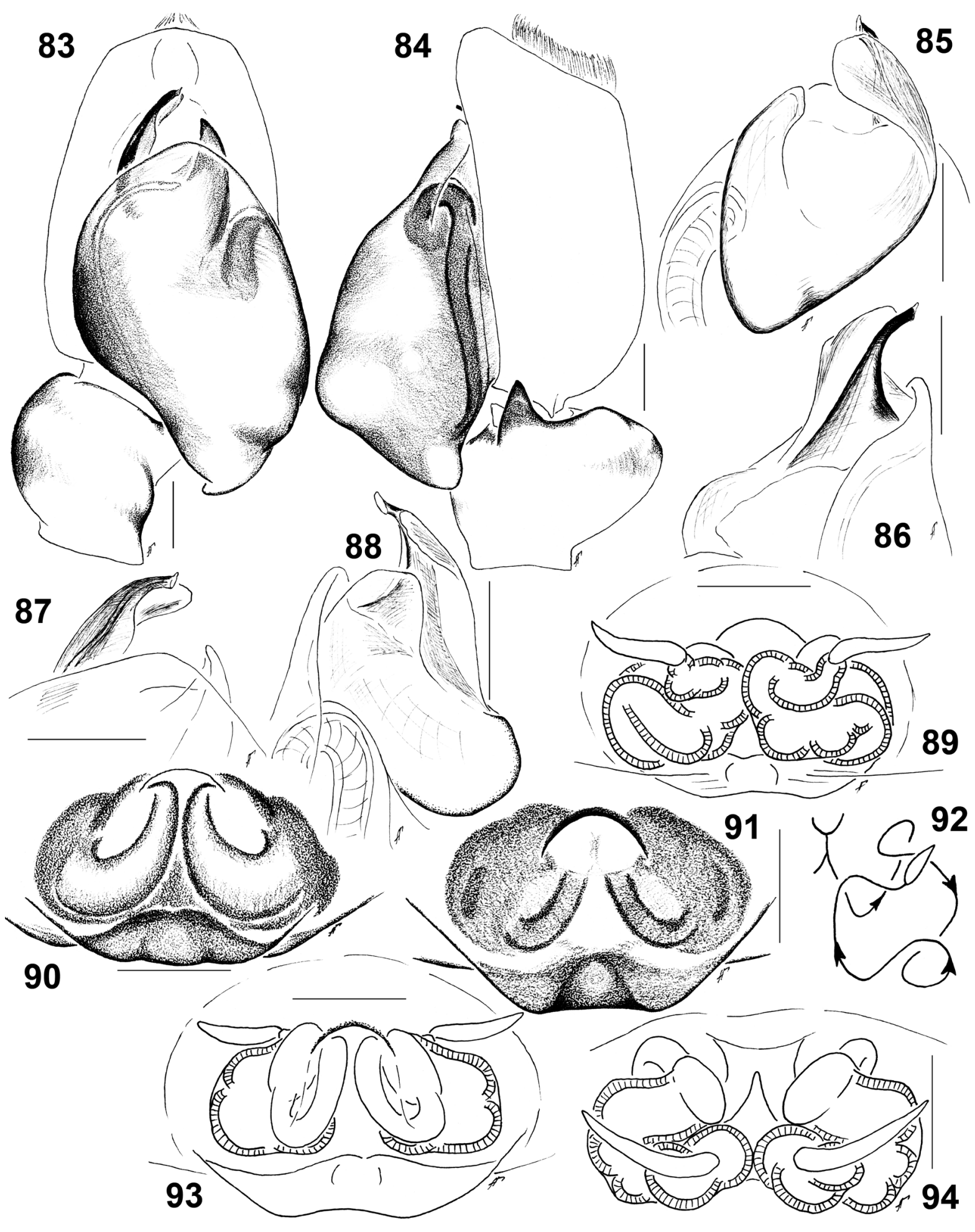

Figs 83-94. Manzuma kenyaensis (Dawidowicz \& Wesołowska, 2016) gen. et comb. nov., $\widehat{\jmath}$ from Kwaisagat (MMUE G 7572.12) (83-88), ㅇ from Kamatira (MMUE G7572.11) (90) and Kwaisagat (MMUE G 7572.13) (89, 91-94). 83-84. Male palp. 83. Ventral view. 84. Retrolateral view. 8588. Embolic division. 85. Dorsal view. 86. Prolateral view. 87. Ventral view. 88. Retrolateral view. 89. Spermathecae, dorsal view. 90-91. Epigyne, ventral view. 92. Diagrammatic course of the insemination ducts. 93-94. Spermathecae. 93. Ventral view. 94. Apical view. Scale bars: $0.1 \mathrm{~mm}$. 


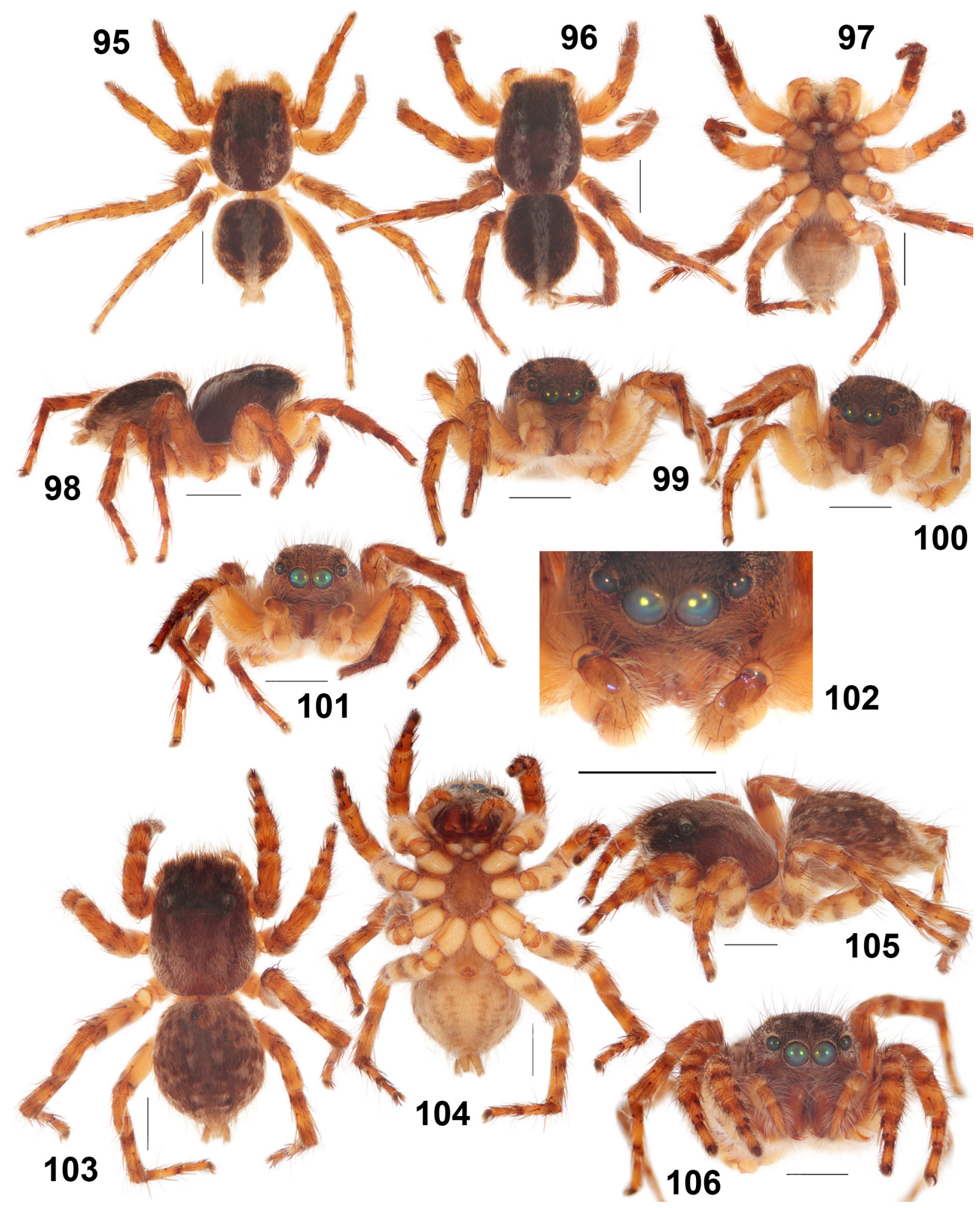

Figs 95-106. Manzuma kenyaensis (Dawidowicz \& Wesołowska, 2016) gen. et comb. nov., § from Kwaisagat (MMUE G 7572.12) (95-102), $q$ from Naro Moru (ISEA 001.8307) (103-106), general appearance. Scale bars: $1 \mathrm{~mm}$. 
a.s.1.; 8 Aug. 1972; J. Murphy leg.; scrub, litter; MMUE G7572.14. - Elgeyo-Marakwet Country • $1{ }^{\jmath}$; Kaibos [=Kaipos] Hill; ca $1.1833^{\circ}$ N, $35.1500^{\circ}$ E; 2600 m a.s.1.; 2 Sep. 1984; J. Murphy leg.; jungle edge; MMUE G7572.47.

\section{Description}

Male (MMUE G7572.12)

Measurements: carapace: $1.80-2.00$ long, $1.60-1.70$ wide, 1.25 high. Abdomen: $1.80-1.90$ long, $1.50-1.60$ wide. Ocular area: $0.80-0.95$ long, $1.15-1.25$ wide anteriorly, $1.05-1.15$ wide posteriorly. Cheliceral length $0.60-0.75$. Clypeal height 0.25. Diameter of AME 0.35-0.400. Length of leg segments: I $1.30+0.65+0.70$ $+0.45+0.45$ (3.55); II $1.25+0.60+0.65+0.50+0.45$ (3.20); III $1.70+0.80+0.80+1.00+0.60$ (4.90); IV $1.50+0.75+0.80+1.00+0.60$ (4.65). Leg spination: I: Fm d 0-1-1-5; Pt pr and rt 1; Tb d 0-0 or 1-0, pr 1-1-1, v 2-2-2 ap; Mt pr and rt 1-1 ap, v 2-2 ap. II: Fm d 0-1-2-5; Pt pr and rt 1; Tb d 1-0; pr 1-1-1, rt 1-0-0 or 1-1-0; v 1-1-2 ap; Mt pr and rt 1-1ap, v 2-2 ap. III: Fm d 0-1-3-5; Pt pr and rt 1; Tb d 1-0-0, pr 1-1-1-0 or 1-1-1-1, rt 1-1-1-1, v 1-0-2 ap; Mt d 1-1-0, pr and rt 1-0-2 ap, v 2-0-2 ap. IV: Fm d 0-1-2-5; Pt pr and rt 1; Tb d 1-0-0, pr and rt 1-1-1-1, v 1-0-2 ap; Mt d 1-1-0, pr 1-1-2 ap, rt 1-0-2 ap, v 1-1-2 ap. Coloration (in alcohol; Figs 95-102). Carapace brown, eye field dark brown, covered with brownish-white scales, with two longitudinal stripes of white scales running from AME to the rear margin of the carapace. Sternum yellow-brown. Endites and labium brownish yellow. Chelicerae brown-yellow. Clypeus and cheeks brown, sparsely covered with long whitish-yellow hairs. Abdomen: dorsum dark brown, medially with longitudinal white stripe; ventral greyish-yellow. Book-lung covers grayish-yellow. Spinnerets brownish yellow. All legs brownish yellow. Femora of all legs apically brown. Femora I densely covered with long whitish-yellow hairs. Patellae, tibiae, metatarsi and tarsi of all legs brown, in some specimens not. Palps yellow, covered with long whitish-yellow hairs. Palpal patella almost without hairs dorsaly, with a few apical bristles, iridescent lustrous, yellow-brownish to brown. Cymbium yellow. Palpal structure as in Figs 83-88: palpal tibia with dorsal bulge, embolus thin in apical part with slightly widened tip, apical projection well developed.

Female (the smallest ISEA 001.3807, the biggest MMUE G7572.13)

Measurements: carapace: 2.50-2.80 long, 2.10-2.30 wide, 1.30-1.60 high. Abdomen: 2.50-3.00 long, 2.10-2.70 wide. Ocular area: $1.00-1.10$ long, $1.40-1.50$ wide anteriorly, $1.35-1.45$ wide posteriorly. Cheliceral length $0.80-1.00$. Clypeal height $0.20-0.30$. Diameter of AME 0.40-0.45. Length of leg segments: I $1.50+0.80+0.90+0.60+0.55$ (4.35); II $1.50+0.80+0.80+0.60+0.55$ (4.25); III $2.00+$ $1.10+1.10+1.20+0.65(6.05) ;$ IV $1.80+0.90+1.20+1.30+0.80(6.00)$. Leg spination: I: Fm d $0-1-1-$ 4; Tb pr 0-0 or 0-1, v 2-2-2 ap; Mt pr 1-1 ap, v 2-2 ap. II: Fm d 0-1-2-5; Tb pr 0-1, v 1-1-2 ap; Mt pr 1-1 ap, v 2-2 ap. III: Fm d 0-1-2-4; Pt pr and rt 1; Tb d 1-0-0, pr and rt 1-1-1, v 1-0-2 ap; Mt d 1-1-0, pr and rt 1-0-2 ap, v 2-0-2 ap. IV: Fm d 0-1-1-2; Pt pr and rt 1; Tb d 1-0-0, pr and rt 1-1-1, v 1-0-2 ap; Mt d 1-1-0, pr 1-1-2 ap, rt 1-0-2 ap, v 1-1-2 ap. Coloration (in alcohol; Figs 103-106). Carapace brown, eye field dark brown, covered with whitish transparent scales, with broad longitudinal white stripe medially, formed two lateral white stripes of white scales running from PLEs to the rear margin of the carapace. Eye field with short white longitudinal stripe of white scales running from AMEs to one third of length of eye field; around PME with two small patches of white scales. Sternum, endites and labium yellowish-brown. Chelicerae brown. Clypeus and cheeks brown, sparsely covered with long transparent white hairs. Cheeks with white stripes of scales running from outer rim of AME's to lateral sides of carapace. Abdomen: dorsum brown, medially with two longitudinal rows of white spots, with white patches laterally; venter brownish yellow, with numerous longitudinal rows of brown spots. Book-lungs covers yellow-brown. Spinnerets yellow. All legs brown-yellow, with brown patches and semi-rings. Palps yellow-brown. Epigyne and spermathecae as in Figs 89-94: introductory parts of the insemination ducts long, running down then up; epigynal pocket low, central structure is $1 / 3$ of epigynal hight, accessory glands small, almost invisible.

\section{Distribution}

Kenya (Fig. 200). 
Manzuma lympha (Próchniewicz \& Heçiak, 1994) gen. et comb. nov. Figs 107-130, 200

Aelurillus lymphus Próchniewicz \& Heçiak, 1994: 34, figs 1a-f; $\widehat{o}$ holotype from NHRS, examined.

Rafalus lymphus - Prószyński 1999: 100.

\section{Diagnosis}

By the body coloration, M. lympha is most similar to $M$. jocquei and $M$. tanzanica gen. et sp. nov. The males can be distinguished from those of $M$. jocquei by the smaller apical projection (ApP), with its tip pointed ventrad (bigger and pointed dorsad in M. jocquei) (cf. Figs 109, 111 and 57-58, 64 correspondingly); the tibial apophysis narrow in M. lympha (Fig. 108) while it is broad in M. jocquei and M. tanzanica gen. et sp. nov. (Figs 61 and 188, correspondingly). From the latter species, M. lympha can be distinguished by the larger ApP (small, poorly visible in M. tanzanica gen. et sp. nov.) (cf. Figs 111 and 192). The females of M. lympha are indistinguishable from those of M. jocquei and M. nigritibia, but can be separated from those of M. botswana gen. et sp. nov. and M. petroae gen. et sp. nov. by the absence of white scaly stripes running from the AME's outer rim to the lateral sides of carapace (cf. Figs 129, 82, 152, 44 and 180).

\section{Material examined}

\section{Holotype}

KENYA $-\widehat{\partial}$, holotype of Aelurillus lymphus; Marsabit Country, Mountain forest at the crates rim of Gof Sokorte Guda ("Lake Paradise"); ca $2.2667^{\circ}$ N, 37.9333 E; 15 Jan. 1975; T. Krønestedt leg.; NHRS 000070049.

\section{Paratype}

KENYA $・ 1$; ; same collection data as for holotype; NHRS 000070049.

\section{Other material}

KENYA • Marsabit Country 1 1 ; same collection data as for holotype; NHRS. - Baringo Country - $1 \mathrm{O}^{\uparrow}$; Baringo Lake; ca $0.6167^{\circ} \mathrm{N}, 39.0667^{\circ} \mathrm{E}$; $1100 \mathrm{~m}$ a.s.1.; 37 Jul. 1974; J. Murphy leg.; grass near hot springs; MMUE G7572.45. - Nakuru Country • 1 đo; Masai Mara; $1.1405^{\circ}$ S, $35.2052^{\circ}$ E; $1753 \mathrm{~m}$ a.s.1.; 3 Jan. 1996; W. Braunstein leg.; camp, high grass; sweepnetting; SMF 69776.

\section{Description}

Male (the smallest paratype, the biggest holotype, coloration and leg spination SMF 69776) Measurements: carapace: 1.80-2.00 long, 1.45-1.55 wide, 1.10 high. Abdomen: 1.40-1.60 long, $1.10-1.20$ wide. Ocular area: $0.85-0.90$ long, $1.10-1.25$ wide anteriorly, $1.05-1.20$ wide posteriorly. Cheliceral length 0.60. Clypeal height 0.20. Diameter of AME 0.35. Length of leg segments (Holotype): I $1.10+0.60+0.65+0.50+0.50(3.35) ;$ II $1.00+0.60+0.60+0.50+0.50(3.20) ;$ III $1.60+0.75+$ $0.80+0.90+0.65$ (4.70); IV $1.45+0.65+0.80+1.10+0.65$ (4.65). Leg spination: I: Fm d 0-1-1-5; Pt pr and rt 1; Tb pr 1-1-1, rt 0-1-0, v 2-2-2 ap; Mt pr and rt 1-1 ap, v 2-2 ap. II: Fm d 0-1-2-5; Pt pr and rt 1; Tb d 1-0-0; pr 1-1-1, rt 0-1-0; v 1-2-2 ap; Mt pr and rt 1-1ap, v 2-2 ap. III: Fm d 0-1-3-5; Pt pr and rt 1; Tb d 1-0-0, pr and rt 1-1-1-1, v 1-0-2 ap; Mt d 1-1-0, pr and rt 1-0-2 ap, v 1-1-2 ap. IV: Fm d 0-1-2-5; Pt pr and rt 1; Tb d 1-0-0, pr and rt 1-1-1-1, v 1-0-2 ap; Mt d 1-1-0, pr 1-1-2 ap, rt 1-0-2 ap, v 1-1-2 ap. Coloration (in alcohol; Figs 117-126). Carapace brown, eye field dark brown, covered with white scales, with two longitudinal stripes of dense white scales, sides covered with white scaly stripes. Sternum yellow-brown. Endites and labium yellow-brown. Chelicerae yellow-brown to brown. Clypeus and cheeks brown, densely covered with long white hairs; apical half of cheeks under ALEs covered with short brown scales. Abdomen: dorsum brown, medially with longitudinal white 
stripe; ventral yellow. Book-lung covers grey-yellow. Spinnerets brownish yellow. All legs yellow. Patellae, tibiae, metatarsi and tarsi of all legs brownish yellow. Palps yellow, covered with long white hairs; cymbium brownish yellow. Palpal structure as in Figs 107-112: apical projection well developed, pointed ventrally; embolic base round, divided to two well visible parts.

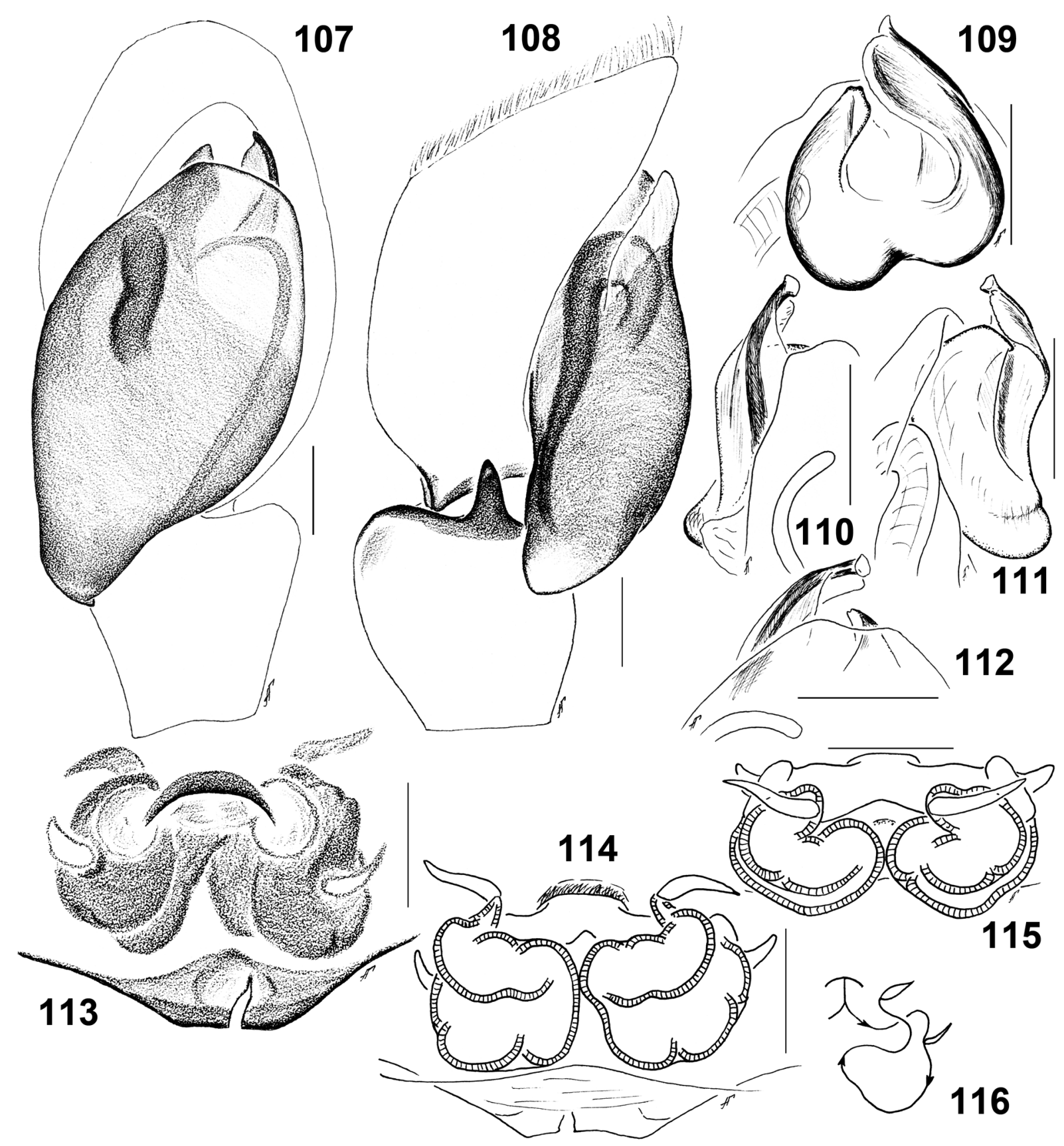

Figs 107-116. Manzuma lympha (Próchniewicz \& Heçiak, 1994) gen. et comb. nov., holotype (107108), paratype (109-112) and $q$ from Gof Sokorte Guda (113-116). 107-108. Male palp. 107. Ventral view. 108. Retrolateral view. 109-112. Embolic division. 109. Dorsal view. 110. Prolateral view. 111. Retrolateral view. 112. Ventral view. 113. Epigyne, ventral view. 114-115. Spermathecae. 114. Dorsal view. 115. Apical view. 116. Diagrammatic course of the insemination ducts. Scale bars: $0.1 \mathrm{~mm}$. 


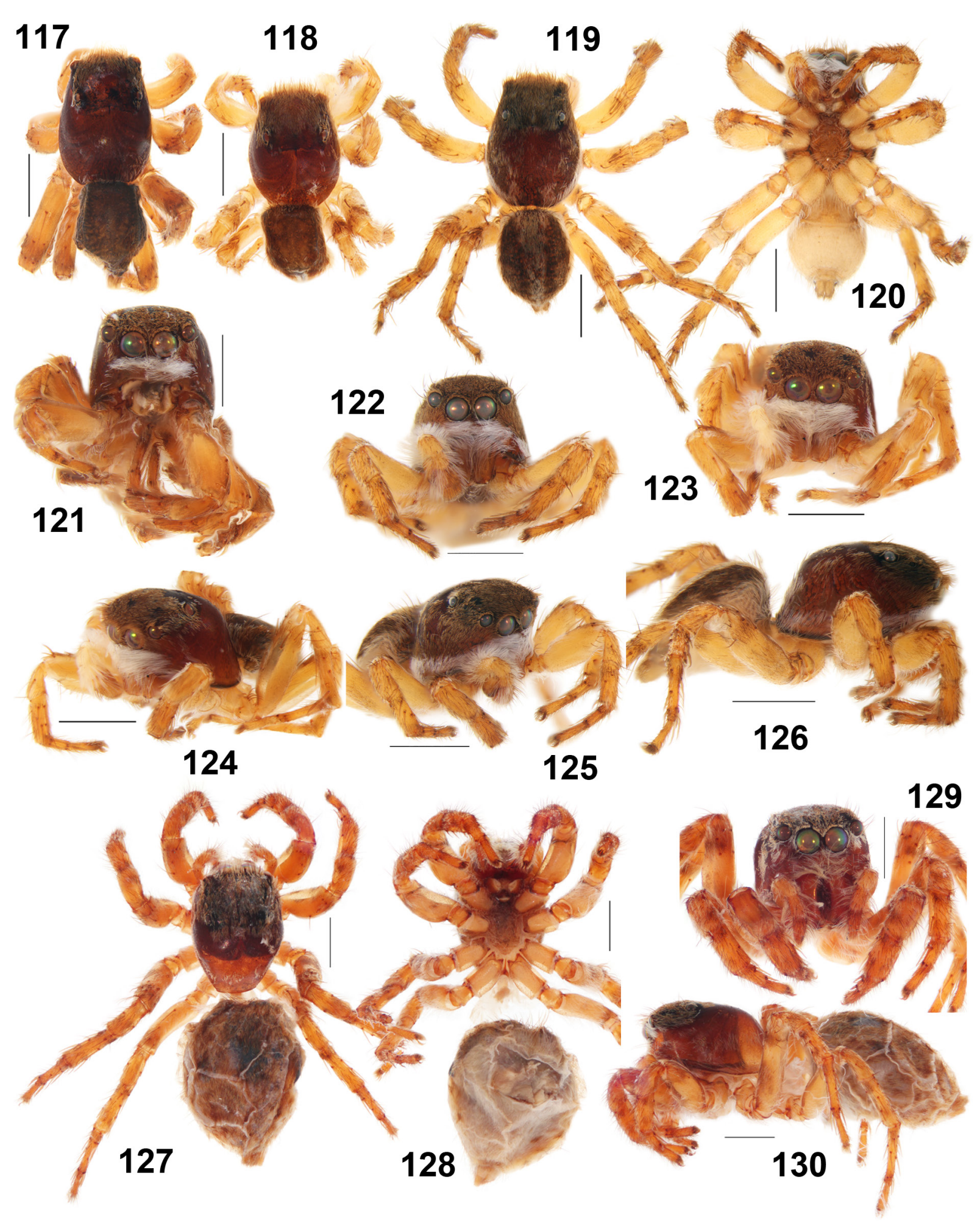

Figs 117-130. Manzuma lympha (Próchniewicz \& Heçiak, 1994) gen. et comb. nov., holotype (117, 121), paratype $(118,123-124), \widehat{o}$ from Masai Mara (SMF 69776) $(119-120,122,125-126)$ and $\bigcirc$ from type locality (127-130), general appearance. Scale bars: $1 \mathrm{~mm}$. 


\section{Female}

Measurements: carapace: 2.70 long, 1.90 wide, 1.40 high. Abdomen: 3.20 long, 2.70 wide. Ocular area: 1.10 long, 1.40 wide anteriorly, 1.35 wide posteriorly. Cheliceral length 0.90 . Clypeal height 0.25 . Diameter of AME 0.45. Length of leg segments: I $1.30+0.80+0.80+0.50+0.50$ (3.90); II $1.25+0.80$ $+0.80+0.60+0.50$ (3.95); III $1.90+0.90+1.10+1.20+0.65(5.75) ;$ IV $1.70+0.80+1.10+1.35+$ 0.65 (5.60). Leg spination: I: Fm d 0-1-1-4; Tb v 2-2-2 ap; Mt pr 1-1 ap, v 2-2 ap. II: Fm d 0-1-2-5; Tb pr 0-1, v 1-1-2 ap; Mt pr 1-1 ap, v 2-2 ap. III: Fm d 0-1-2-4; Pt pr and rt 1; Tb d 1-0-0, pr and rt 1-1-1, v 1-0-2 ap; Mt d 1-1-0, pr and rt 1-0-2 ap, v 1-1-2 ap. IV: Fm d 0-1-1-2 or 0-1-1-3; Pt pr and rt 1; Tb d 1-0-0, pr and rt 1-1-1, v 1-0-2 ap; Mt d 1-1-0, pr 1-1-2 ap, rt 1-0-2 ap, v 1-1-2 ap. Coloration (in alcohol; Figs 127-130, body in a bad condition). Carapace brown, eye field dark brown, covered with whitish scales. Sternum brown-yellow. Endites and labium brown. Chelicerae brown. Clypeus and cheeks yellow-brown, covered with long white hairs. Abdomen: dorsum brown, covered with short brown hairs; venter yellow-grey, covered with white hairs. Book-lungs covers yellow-grey. Spinnerets brownyellow. All legs and palps brownish-yellow, palps covered with white hairs. Epigyne and spermathecae as in Figs 113-116: epigynal pocket low, central structure is $1 / 3$ of epigynal height; accessory glands well developed and well visible from dorsal and ventral view of epigyne.

\section{Distribution}

Kenya (Fig. 200).

Manzuma nigritibia (Caporiacco, 1941) gen. et comb. nov.

Figs 123-145, 200

Saitis nigritibiis Caporiacco, 1941: 145, fig. 63; तै holotype from MSNF, examined.

Aelurillus reconditus Wesołowska \& van Harten, 1994: 2, figs 3-5; 9 holotype from MRAC, examined.

Syn. nov.

Aelurillus nigritibiis - Prószyński 1987: 1; đ̂̉ only, transfered from Saitis.

Rafalus nigritibiis - Prószyński 1999: 101, figs 41-42.

Aelurillus reconditus - Proszynski 2003: 36.

Aelurillus lymphus - Wesołowska \& Tomasiewicz 2008: 4; misidentification.

Rafalus lymphus - Wesołowska \& van Harten 2010: 56, pl. 23, figs 83-86; misidentification.

\section{Diagnosis}

Manzuma nigritibia is most similar to M. jocquei and M. lympha in body coloration. The males can be distinguished by the coloration of the clypeus and cheeks. The clypeus has a diamond-shaped patch of brown hairs between AME and on the upper half of the clypeus. The cheeks are covered with a long white hairs from the ALEs to the margin of carapace (Figs 145, 147), while in M. jocquei and $M$. lympha the upper half of the cheeks under ALEs are covered with a short brown scales and the basal half covered with a long white hairs (Figs 75-77 and 121-125 correspondingly). The females cannot be distinguished from $M$. jocquei and $M$. lympha but can be distinguished from $M$. botswana gen. et sp. nov. and M. petroae gen. et sp. nov. by the absence of white stripes of scales running from the outer rim of the AME's to the lateral sides of carapace (cf. Figs 152, 82, 129, 44 and 180 correspondingly).

\section{Material examined}

\section{Holotypes}

ETHIOPIA $\bullet \widehat{0}$, holotype of Saitis nigritibiis; "Foci del Sagan, Missione Biologico Sagan-Omo" [mouth of Sagan, biological mission Sagan-Omo]; ca 5.2167 N, 37.0167 E; 19 Jun. 1939; E. Zavattari leg.; MSNF, 439. 


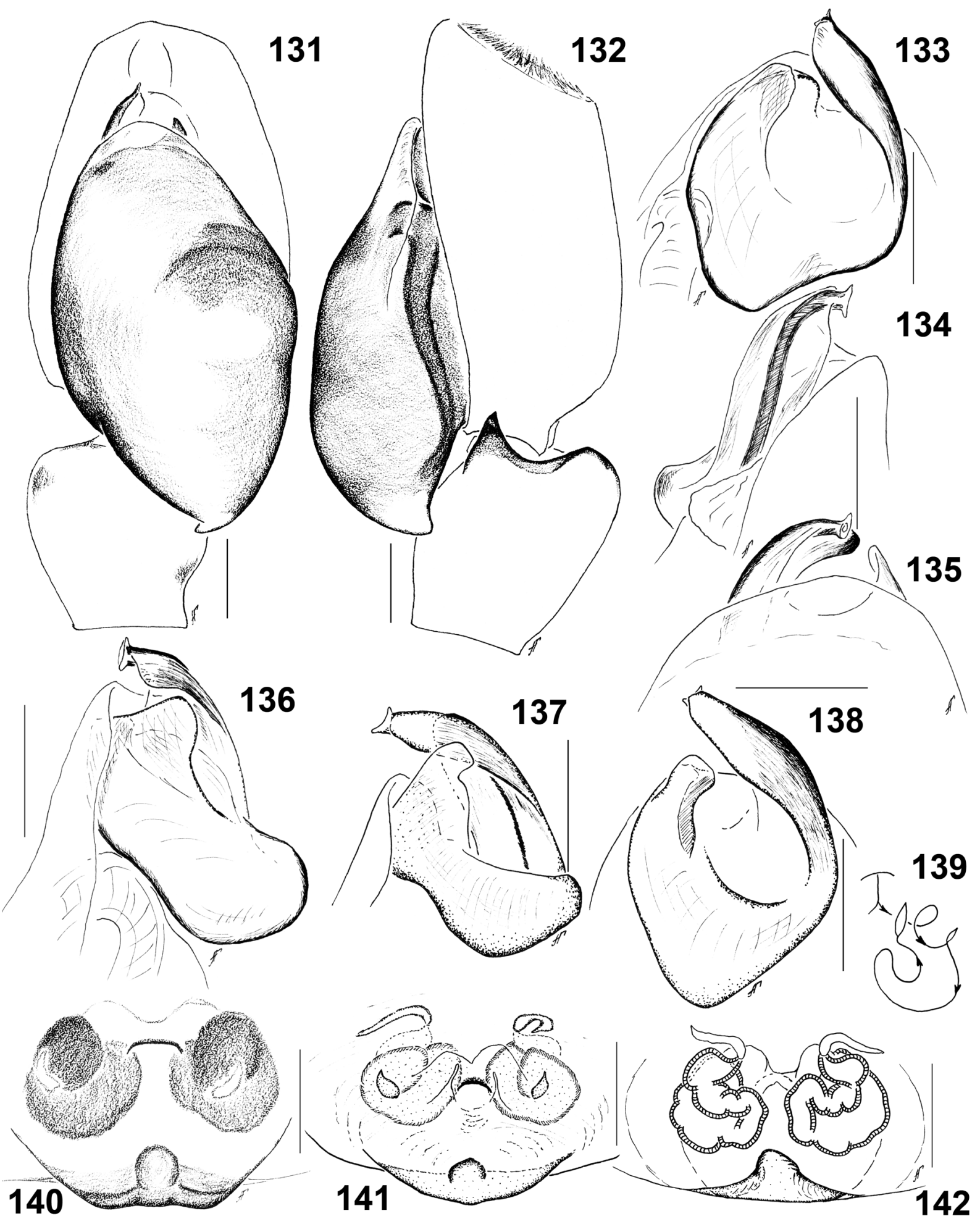

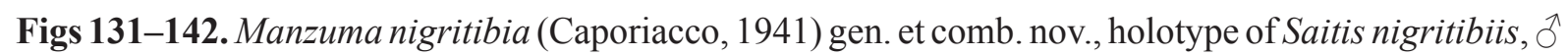

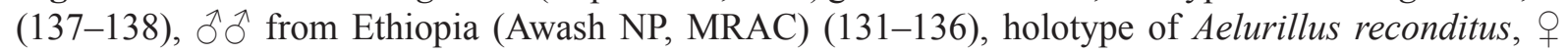
(139-142). 131-132. Male palp. 131. Ventral view. 132. Retrolateral view. 133-138. Embolic division. 133, 138. Dorsal view. 134. Prolateral view. 135. Ventral view. 136-137. Retrolateral view. 139. Diagrammatic course of the insemination ducts. 140-142. Epigyne. 140. Ventral view. 141. Ventroapical view. 142. Spermathecae, dorsal view. Scale bars: $0.1 \mathrm{~mm}$. 
YEMEN • + , holotype of Aelurillus reconditus; Al Mahwit Governorate, Wadi Surdud [=Wādī Surdūd]; ca $15.2667^{\circ}$ N, $43.2000^{\circ}$ E; 28-29 Dec. 1991; A. van Harten leg.; MRAC 201.301.

\section{Other material}

ETHIOPIA • 1 đ’; Awash N.P., Awash River below falls; ca $8.8333^{\circ} \mathrm{N}, 40.0000^{\circ}$ E; 13 May 1987; A. Russell-Smith leg.; , on sandy beach; MRAC.

YEMEN • $1 \partial^{\top}$; Al-Lahima; ca $15.4000^{\circ} \mathrm{N}, 43.5333^{\circ}$ E; 5 Jun.-24 Jul. 2001; A. van Harten leg.; Malaise trap; MRAC 212.800.

\section{Description}

Male (specimen from Ethiopia, MRAC)

Measurements: carapace: 1.70 long, 1.50 wide, 1.20 high. Abdomen: 1.60 long, 1.30 wide. Ocular area: 0.90 long, 1.30 wide anteriorly, 1.20 wide posteriorly. Cheliceral length 0.55 . Clypeal height 0.25 . Diameter of AME 0.35. Length of leg segments: I $1.10+0.55+0.60+0.50+0.40$ (3.15); II $1.10+0.60$ $+0.60+0.45+0.40(3.15) ;$ III $1.50+0.70+0.80+0.70+0.60(4.30) ;$ IV $1.30+0.55+0.80+0.85+$ 0.60 (4.10). Leg spination: I: Fm d 0-1-1-5; Pt pr and rt 1; Tb d 1-0-0, pr 1-1-1, rt 0-1-0, v 2-2-2 ap; Mt pr and rt 1-1 ap, v 2-2 ap. II: Fm d 0-1-2-5; Pt pr and rt 1; Tb d 1-0-0; pr 1-1-1, rt 0-1-0; v 1-1-2 ap; Mt pr and rt 1-1ap, v 2-2 ap. III: Fm d 0-1-2-5 or 0-1-3-5; Pt pr and rt 1; Tb d 1-0-0, pr and 1-1-1, v 1-0-2 ap; Mt d 1-1-0, pr and rt 1-0-2 ap, v 2-0-2 ap. IV: Fm d 0-1-1-5; Pt pr and rt 1; Tb d 1-0-0, pr 1-1-1-0, rt 1-1-1-1, v 1-0-2 ap; Mt d 1-1-0, pr and rt 1-0-2 ap, v 1-1-2 ap. Coloration (in alcohol; Figs 143149). Carapace brown, eye field dark brown, covered with brown scales, with two longitudinal white stripes of scales running from PLEs to the rear margin of the carapace; sides covered with white stripes of scales. Sternum, endites, labium and chelicerae yellow-brown. Clypeus and cheeks brown-yellow, covered with long yellow-white hairs, except small area beneath AMEs; clypeus with diamond-shaped patch of brown hairs between AME and on upper half of clypeus. Abdomen: dorsum brown, medially with longitudinal white stripe; ventral brownish yellow. Book-lung covers brownish yellow. Spinnerets brown-yellow. All legs yellow. Femora I prolaterally densely covered with long yellow-white hairs. Tibiae, metatarsi and tarsi I brown, ventrally dark-brown. Palps yellow; palpal femur covered with long white hairs; cymbium brown. Palpal structure as in Figs 131-138: tegulum with small, almost invisible proximal projection; apical projection medium in size; TA broad in middle part, apically getting narrow.

Female (holotype of Aelurillus reconditus)

Measurements: carapace: 2.50 long, 1.90 wide, 1.40 high. Abdomen: 2.20 long, 1.90 wide. Ocular area: 1.20 long, 1.40 wide anteriorly, 1.40 wide posteriorly. Cheliceral length 0.80 . Clypeal height 0.20 . Diameter of AME 0.45. Length of leg segments: I $1.10+0.80+0.80+0.60+0.50$ (3.80); II $1.10+0.80$ $+0.70+0.50+0.50(3.60) ;$ III $1.70+1.00+1.00+1.00+0.60(5.30) ;$ IV $1.50+0.80+1.00+1.20+$ 0.70 (5.20). Leg spination: I: Fm d 0-1-1-4; Tb v 2-2-2 ap; Mt pr 1-1 ap, v 2-2 ap. II: Fm d 0-1-1-5; Tb pr 1-1, v 1-1-2 ap; Mt pr 1-1 ap, v 2-2 ap. III: Fm d 0-1-2-4; Pt pr and rt 1; Tb d 1-0-0, pr and rt 1-1-1, v 1-0-2 ap; Mt d 1-1-0, pr and rt 1-0-2 ap, v 1-1-2 ap. IV: Fm d 0-1-1-2; Pt pr and rt 1; Tb d 1-0-0, pr and rt 1-1-1, v 1-0-2 ap; Mt d 1-1-0, pr and rt 1-0-2 ap, v 1-1-2 ap. Coloration (in alcohol; Figs 150153). Carapace brown, eye field dark brown, covered with whitish scales. Sternum brownish yellow. Endites and labium yellow. Chelicerae brownish yellow. Clypeus and cheeks yellow, covered with long yellow-white hairs. Abdomen: dorsum brown, covered with yellowish-white hairs; venter yellow-grey. Book-lungs covers and spinnerets yellow. All legs and palps yellow. Epigyne and spermathecae as in Figs 139-142: copulatory openings almost invisible; epigynal pocket low, central structure is $1 / 3$ of epigynal height.

\section{Distribution}

Ethiopia, Yemen (Fig. 200). 


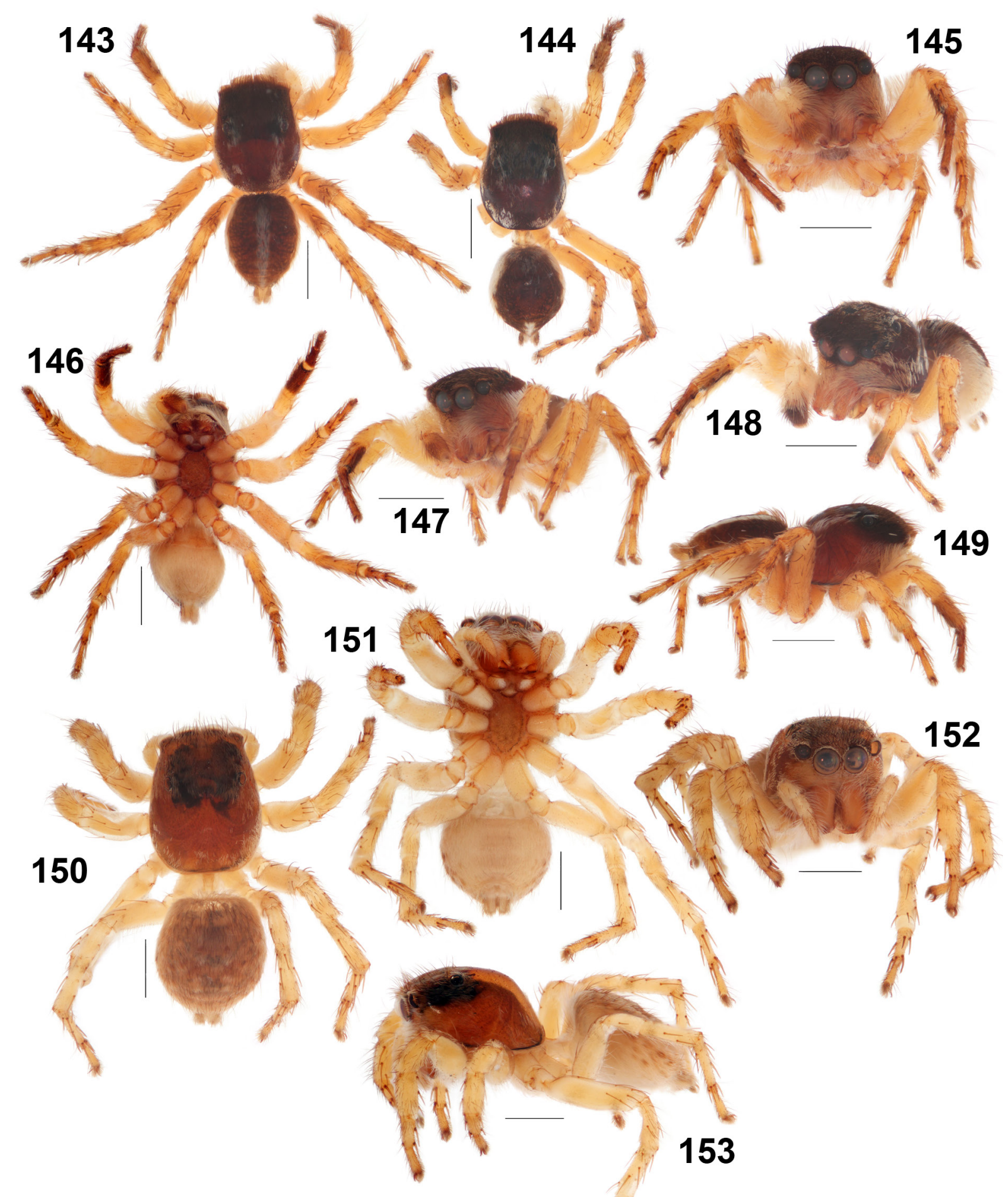

Figs 143-153. Manzuma nigritibia (Caporiacco, 1941) gen. et comb. nov., $\widehat{\partial} \widehat{\partial}$ from Ethiopia (143, 145-147, 149, MRAC) and Yemen (144, 148, MRAC 212.800), holotype of Aelurillus reconditus, + (150-153), general appearance. Scale bars: $1 \mathrm{~mm}$. 


\section{Manzuma petroae gen. et sp. nov. urn:1sid:zoobank.org:act:A77CFC8E-24B1-412D-85F9-D7C5CB2D85A0}

Figs 20-22, 49-51, 154-187, 200

\section{Diagnosis}

Manzuma petroae gen. et sp. nov. is most similar to M. botswana gen. et sp. nov. in body coloration. The males of M. petroae gen. et sp. nov. differ in having the clypeus covered with long white hairs with a diamond-shaped patch of brown hairs between the AME and on the upper half of the clypeus in the center (Figs 170-171, 176-177, 186-187), while in M. botswana gen. et sp. nov. the clypeus is covered with short brown scales, medially with a thin vertical stripe of white hairs (Figs 39, 48). The cheeks in M. petroae gen. et sp. nov. are covered with yellowish white hairs (Figs 170-171, 176-177) while in M. botswana gen. et sp. nov. the cheeks have a thin white line running from the ALEs to sides of carapace (Fig. 38). The apical projection (ApP) in M. petroae gen. et sp. nov. is small, rounded in outline and slightly bent dorsally (Fig. 158), while in M. botswana gen. et sp. nov. the ApP is large and robust (Fig. 31). The females of $M$. petroae gen. et sp. nov. differ in the uniform colour of the eye of specimens preserved in alcohol (Figs 178, 180) and short wide stripe just behinf AMEs of live specimens (Figs 4951), while in M. botswana gen. et sp. nov. the eye field has a short narrow white stripe just behind AMEs (Figs 42, 44).

\section{Etymology}

This species is dedicated to the South African curator of the National Collection of Arachnida at ARC PPRI (Pretoria/Tshwane), Petro Marais.

\section{Material examined}

\section{Holotype}

SOUTH AFRICA • ${ }^{\top}$; KwaZulu-Natal Province, Ithala Game Reserve, Doornkraal Camp; $27.5122^{\circ}$ S, 31.2039 ${ }^{\circ}$ E, 28 Jan. 2014; C. Haddad leg.; hand collecting on ground; NCA 2013/4929.

\section{Paratypes}

SOUTH AFRICA - North-West Province - $1 \delta^{\lambda}$; ca $40 \mathrm{~km}$ NW of Brits; ca $25.3833^{\circ} \mathrm{S}, 27.4500^{\circ}$ E; 1984-1985; R. Watmough leg.; cotton; pitfall traps; MRAC. - Gauteng Province • 1 गे; Pretoria/ Tshwane, Rietondale research campus; ca $25.7167^{\circ}$ S, 28.2167 E; 16 Jul. 1998; J. Nkwana leg.; pitfall traps; NCA 2019/713 • 1 đं; Roodeport, Walter Sisulu National Botanical Garden; $26.0833^{\circ}$ S, $27.8333^{\circ}$ E; 5 Dec. 2015; G.N. Azarkina leg.; by hands; ISEA 001.7212 • 1 O; Midrand; $26.0197^{\circ} \mathrm{S}$, 28.0970 E; 6 Mar. 2006; L. Niemand leg.; waterfall 5 IR; NCA 2009/3732. - Limpopo Province •

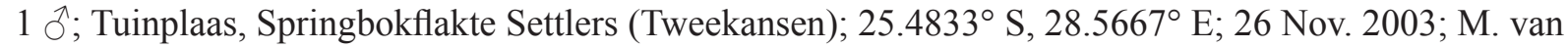
Jaarsveld leg.; grass; pitfall traps; NCA 2016/382. - KwaZulu-Natal Province • 1 q; same collection data as for holotype; NCA 2019/712 • 1 ô, 1 o ; Hluhluwe/Umfolozi NR; ca $28.0667^{\circ} \mathrm{S}, 32.1333^{\circ} \mathrm{E} ; 2$ Dec. 2005; M. Mgobozi leg.; NCA 2007/1998, NCA 2007/2045. - Eastern Cape Province • 1 o; Fort Beaufort, Mpofu Nature Reserve; 32.6100 ${ }^{\circ}$ S, $26.5900^{\circ}$ E; 29 Jan. 2009; S.L. Peinke leg.; thornveld (transect 1); pitfall traps; NCA 2011/826.

\section{Description}

Male (the smallest holotype NCA 2013/4929, the biggest ISEA 001.7212,) Measurements: carapace: $1.70-1.90$ long, $1.30-1.40$ wide, $0.85-0.95$ high. Abdomen: $1.40-1.50$ long, 1.20 wide. Ocular area: $0.75-0.85$ long, $1.00-1.10$ wide anteriorly, $0.95-1.05$ wide posteriorly. Cheliceral length $0.45-0.60$. Clypeal height $0.15-0.20$. Diameter of AME $0.30-0.35$. Length of leg segments: I 0.90 $+0.40+0.50+0.40+0.35(2.55) ;$ II $0.90+0.50+0.50+0.30+0.30(2.50) ;$ III $1.30+0.60+0.60+0.70$ +0.45 (3.65); IV $1.10+0.60+0.60+0.75+0.45$ (3.50). Leg spination: I: Fm d 0-1-1-5; Pt pr and rt 1; 
Tb pr 1-1-1, rt 0-0 (in HT) or 0-1, v 2-2-2 ap; Mt pr and rt 1-1 ap, v 2-2 ap. II: Fm d 0-1-2-5; Pt pr and rt 1; Tb d 1-0-0; pr 1-1-1, rt 1-1-0; v 1-1-2 ap; Mt pr and rt 1-1ap, v 2-2 ap. III: Fm d 0-1-2-5; Pt pr and rt 1; Tb d 1-0-0, pr 1-1-1, rt 1-1-1-1, v 1-0-2 ap; Mt d 1-1-0, pr and rt 1-0-2 ap, v 1-1-2 ap. IV: Fm d 0-1-1-3 (in HT) or 0-1-1(2)-5; Pt pr and rt 1; Tb d 1-0-0, pr and rt 1-1-1-1, v 1-0-2 ap; Mt d 1-1-0, pr and rt 1-1-2 ap, v 1-1-2 ap. Coloration (in alcohol: Figs 168-177; live specimens: Figs 182-187). Carapace brown to dark brown, covered with short brownish scales, with two longitudinal white stripes. Eye field dark brown, almost black, anterior third with short wide white longitudinal stripe. Sternum brownish yellow. Endites and labium yellow-brown. Chelicerae brownish yellow. Clypeus and cheeks brown, covered with yellowish-white hairs, with diamond-shaped patch of brown hairs between AME and on upper half of clypeus. Abdomen: dorsum brown, with median white longitudinal stripe; venter brownish yellow. Book-lung brownish yellow. Spinnerets yellowish-brown. All legs brownish yellow. Femora I with long dense yellow-white hairs. Patellae, tibiae, metatarsi and tarsi of all legs brownish. Palps yellow, covered with long yellow-white hairs. Palps as in Figs 146-152; ventral RTA triangle, well developed; dorsal RTA

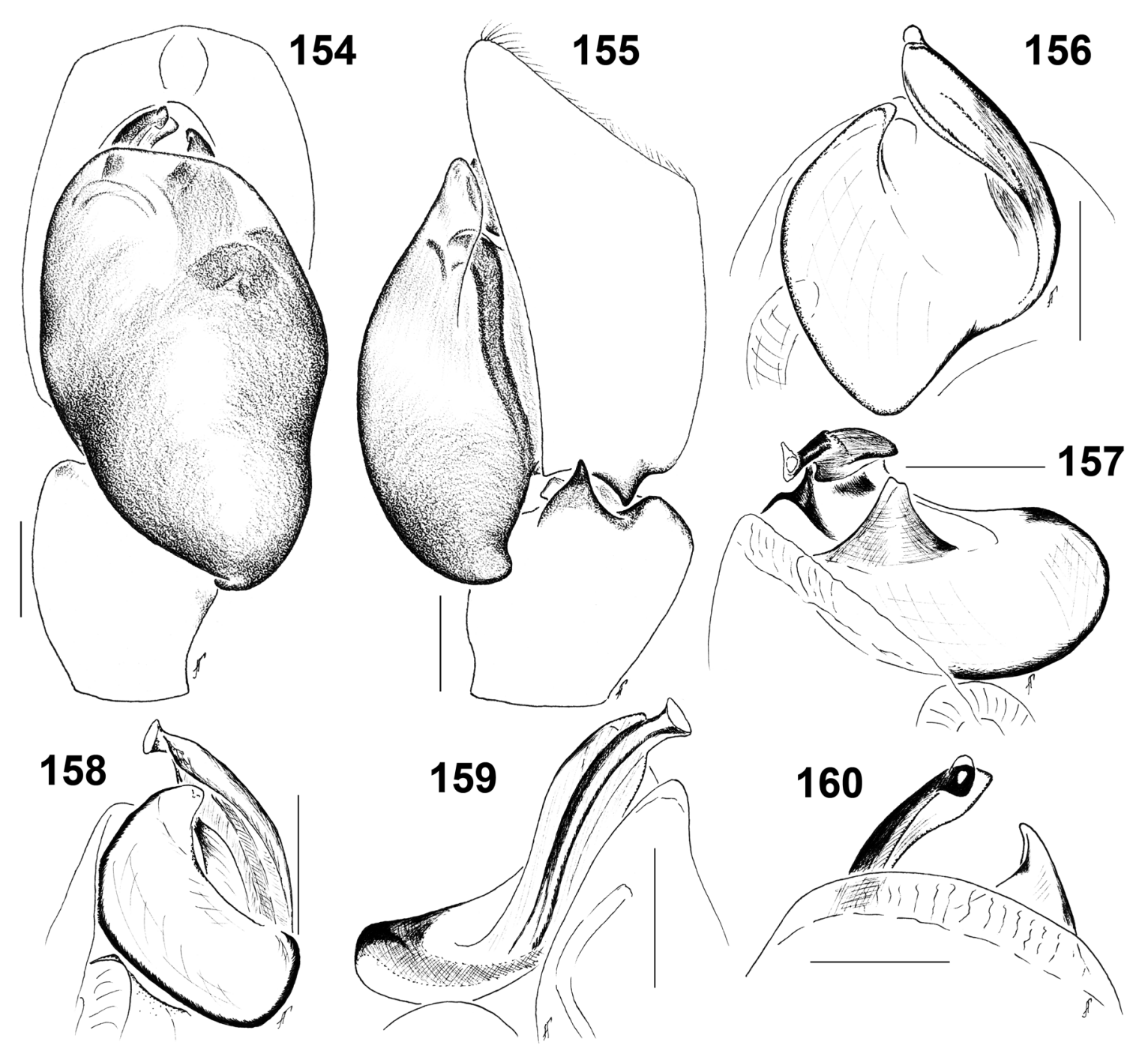

Figs 154-160. Manzuma petroae gen. et sp. nov., holotype, $\widehat{o}(154-155)$ and paratype, $\widehat{o}$ from Tuinplaas (NCA 2016/382) (156-160). 154-155. Male palp. 154. Ventral view. 155. Retrolateral view. 156-160. Embolic division. 156. Dorsal view. 157. Retrolatero-apical view. 158. Retrolateral view. 159. Prolateral view. 160. Ventral view. Scale bars: $0.1 \mathrm{~mm}$. 
small, bulge-shaped; proximal projection rounded, small; embolic base with bifurcated apical projection, basal part with wide prominent lobe; tegulum with visible small tegular process.

Female (the smallest NCA 2007/2045, the biggest NCA 2009/3732)

Measurements: carapace: $1.80-2.10$ long, $1.75-1.85$ wide, $1.10-1.45$ high. Abdomen: $2.30-2.50$ long, 1.80-2.10 wide. Ocular area: $0.90-1.00$ long, $1.25-1.40$ wide anteriorly, $1.20-1.35$ wide posteriorly. Cheliceral length $0.70-0.85$. Clypeal height $0.20-0.25$. Diameter of AME $0.40-0.45$. Length of leg segments: I $1.10+0.70+0.75+0.55+0.45$ (3.55); II $1.10+0.70+0.70+0.60+0.50$ (3.60); III 1.70 $+0.90+0.90+1.00+0.65(5.15) ;$ IV $1.50+0.75+0.90+1.15+0.65$ (4.95). Leg spination: I: Fm d 0-1-1-4; Tb pr 0-1 or 1-1, v 2-2-2 ap; Mt pr 1-1 ap, v 2-2 ap. II: Fm d 0-1-2-4; Tb pr 1-1, v 1-1-2 ap; Mt pr 1-1 ap, v 2-2 ap. III: Fm d 0-1-2-4; Pt pr and rt 1; Tb d 1-0-0, pr and rt 1-1-1, v 1-0-2 ap; Mt d 1-1-0, pr and rt 1-0-2 ap, v 1-1-2 ap. IV: Fm d 0-1-1-2; Pt pr and rt 1; Tb d 1-0-0, pr and rt 1-1-1, v 1-0-2 ap; Mt d 1-1-0, pr 1-1-2 ap, rt 1-0-2 ap, v 1-1-2 ap. Coloration (live specimens: Figs 49-51; in alcohol: Figs 178181). Carapace brown, covered with transparent white scales, with two hardly visible white stripes, without such a stripes in a specimen from Eastern Cape (NCA 2011/826). Sternum brownish yellow. Endites and labium brownish. Chelicerae brown. Clypeus and cheeks yellow-brown, covered with white hairs; cheeks with two narrow lines of whitish dense scales running from AMEs to sides. Abdomen: dorsum brown, with two median lines of white dots; venter grey-yellow. Book-lung brownish yellow. Spinnerets: anteriors pairs yellow, posterior pair yellow-brown. All legs and palps brownish yellow, with brown patches. Epigyne and spermathecae as in Figs 161-167: copulatory openings hardly visible; epigynal pocket high and convex ventrally; accessory glands located in the middle part of insemination ducts.

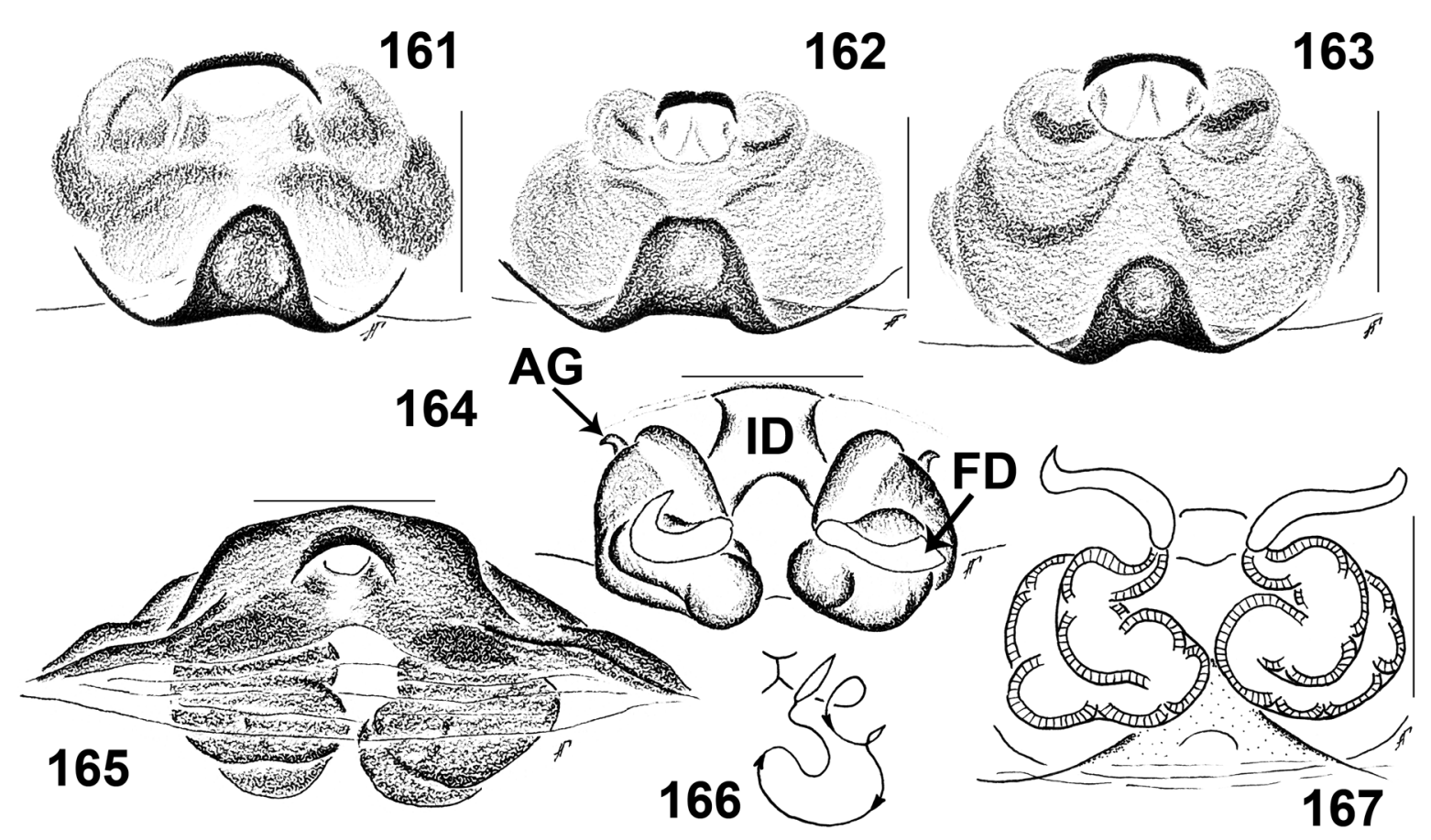

Figs 161-167. Manzuma petroae gen. et sp. nov., paratypes, $q$ ㅇ from Ithala GR $(161,164-165,167$, NCA 2019/712), Midrand (162, NCA 2009/3732) and Mpofu NR (163, NCA 2011/826). 161-163. Epigyne, ventral view. 164. Spermathecae, apical view. 165. Epigyne, basal view. 166. Diagrammatic course of the insemination ducts. 167. Spermathecae, dorsal view. Scale bars: $0.1 \mathrm{~mm}$. 


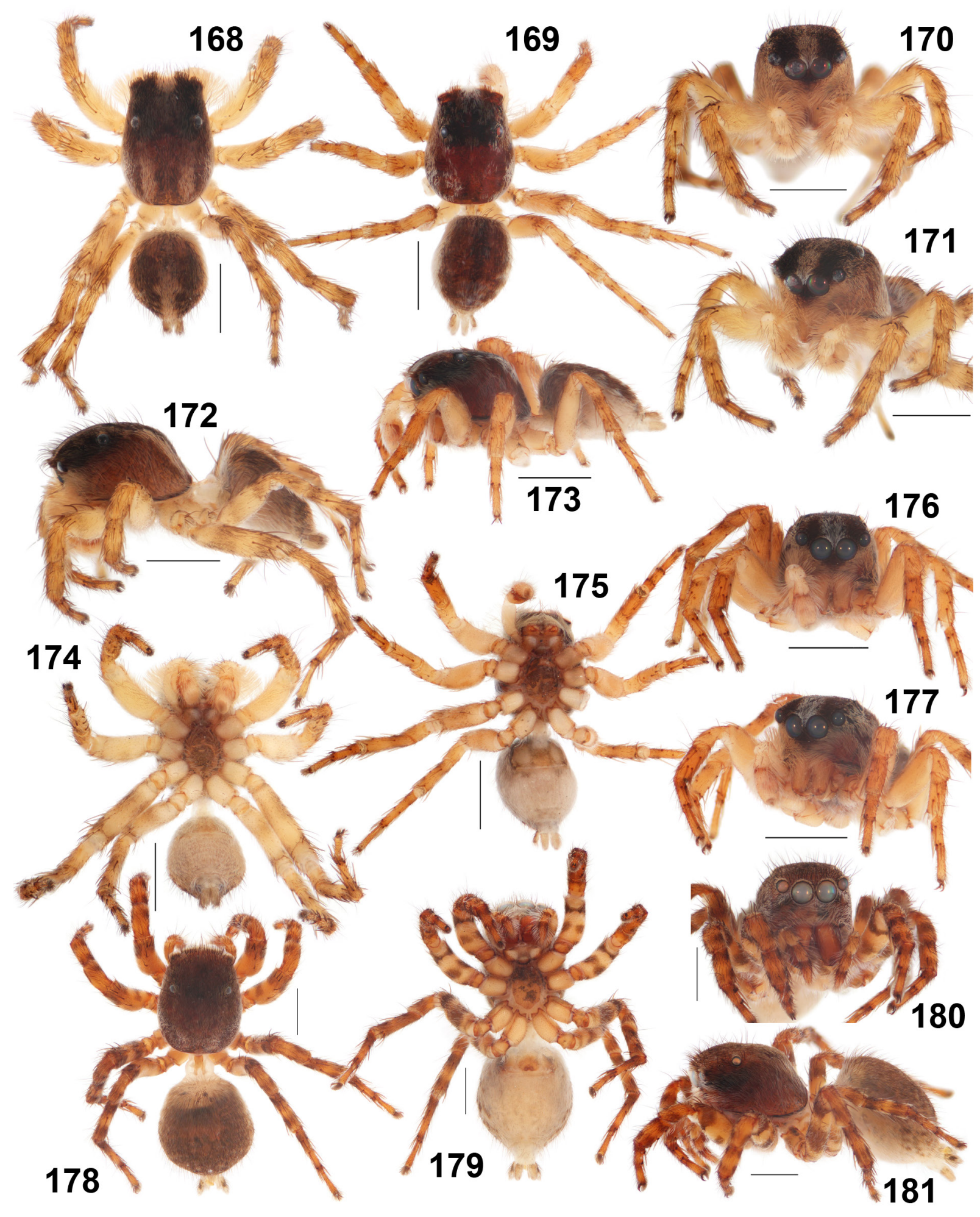

Figs 168-181. Manzuma petroae gen. et sp. nov., paratypes, ồ from Roodeport (168, 170-172, 174, ISEA 001.7212) and Tuinplaas $(169,173,175-177$, NCA 2016/382), paratype, o from Ithala GR (178181, NCA 2019/712), general appearance. Scale bars: $1 \mathrm{~mm}$. 

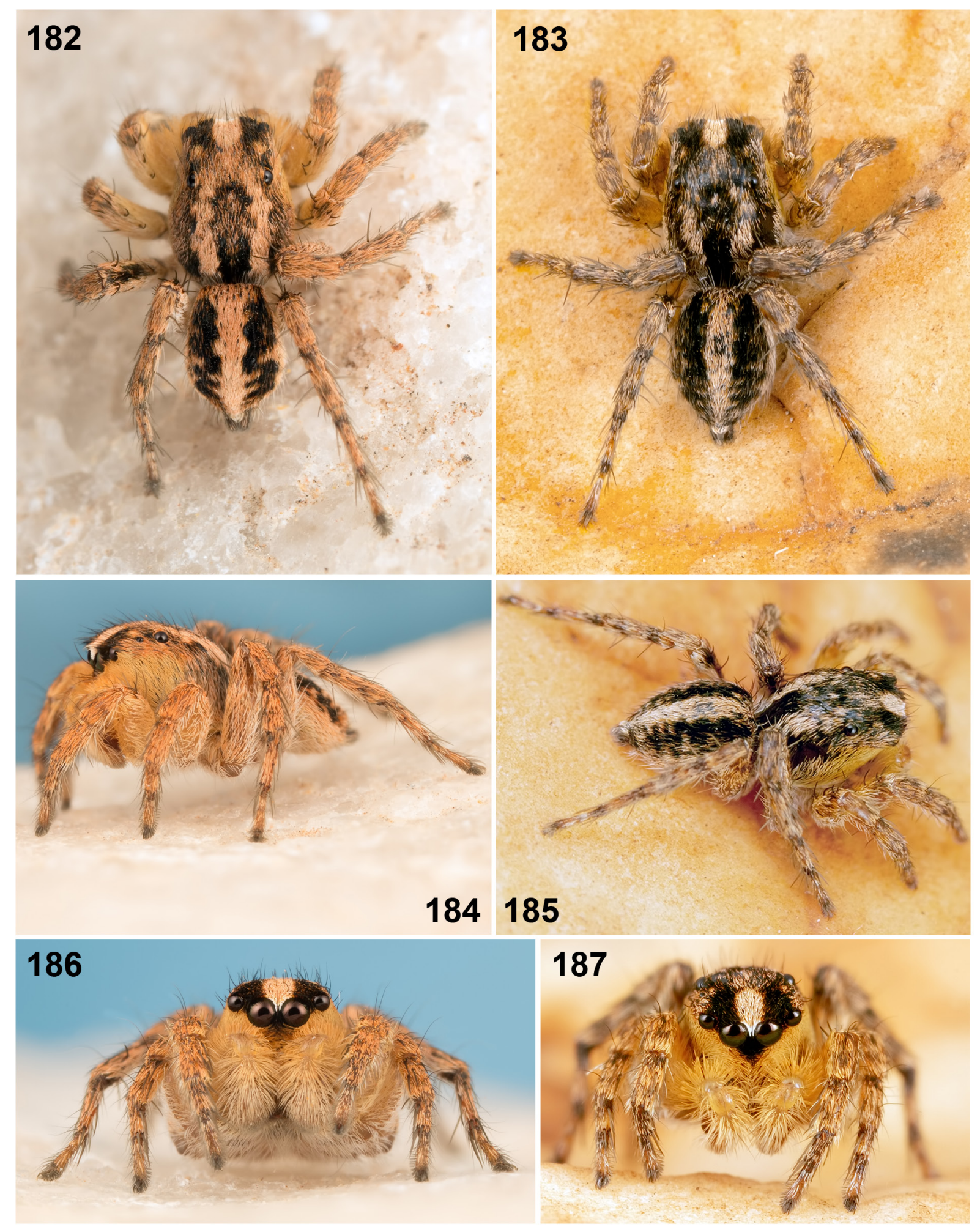

Figs 182-187. Manzuma petroae gen. et sp. nov., general appearance of live $\widehat{\partial}$ from South Africa, photos (C) Vida van der Walt. 


\section{Distribution}

South Africa (Fig. 200).

Manzuma tanzanica gen. et sp. nov.

urn:1sid:zoobank.org:act:78D84EB3-60B3-47B4-8DE8-7514C58E6BBC

Figs $188-200$

Aelurillus lymphus - Wesołowska \& Russell-Smith 2000: 14, figs 2-5.

\section{Diagnosis}

Manzuma tanzanica is most similar to M. jocquei, M. lympha and M. nigritibia in body coloration. The males can be distinguished from $M$. jocquei and $M$. lympha by the poorly developed apical projection (well developed in M. jocquei) (cf. Figs 190, 192, 57-58, 64 and 109, 111 correspondingly); from M. nigritibia it can be distinguished by the coloration of the clypeus and cheeks. The upper half of cheeks under ALEs are covered with short brown scales and the basal half of cheeks covered with long white hairs (Figs 196-197) while in M. nigritibia the clypeus has a diamond-shaped patch of brown
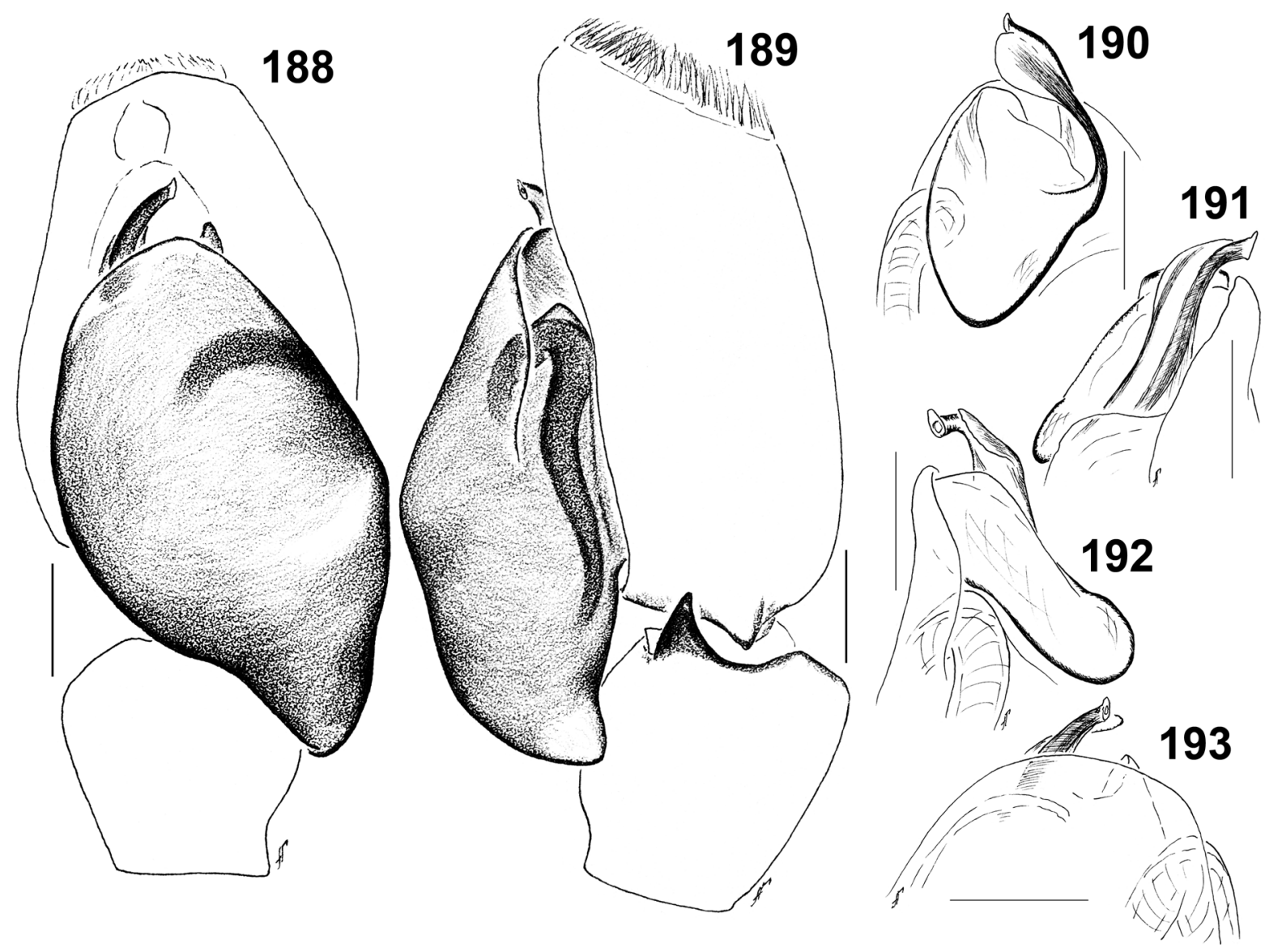

Figs 188-193. Manzuma tanzanica gen. et sp. nov., holotype, $\widehat{\jmath}$ and paratype. 188-189. Male palp. 188. Ventral view. 189. Retrolateral view. 190-193. Embolic division. 190. Dorsal view. 191. Prolateral view. 192. Retrolateral view. 193. Ventral view. Scale bars: $0.1 \mathrm{~mm}$. 
hairs between AME and on upper half of clypeus and the cheeks covered with long white hairs from ALEs to margin of carapace (Figs 145, 147).

\section{Etymology}

The specific epithet is named after the country of origin, Tanzania.

\section{Material examined}

\section{Holotype}

TANZANIA • đ’; Mkomazi G.R., Ibaya Camp; ca 4.0000 S, 38.0000 E; 21-22 Nov. 1994; A. RussellSmith leg.; burnt grassland; MRAC 208.024.

\section{Paratypes}

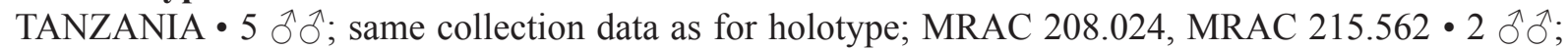
same locality as for holotype; Feb. 1994; A. Russell-Smith leg.; pitfall traps; grassland; MRAC 208.029.

\section{Description}

Male (holotype, MRAC 208.024)

Measurements: carapace: 1.75 long, 1.50 wide, 1.10 high. Abdomen: 1.95 long, 1.50 wide. Ocular area: 0.95 long, 1.25 wide anteriorly, 1.20 wide posteriorly. Cheliceral length 0.55 . Clypeal height 0.20 . Diameter of AME 0.30. Length of leg segments: I $1.10+0.60+0.60+0.50+0.50$ (3.30); II $1.00+0.60$ $+0.65+0.50+0.45(3.20) ;$ III $1.50+0.80+0.80+0.90+0.65(4.65) ;$ IV $1.30+0.65+0.85+1.00$

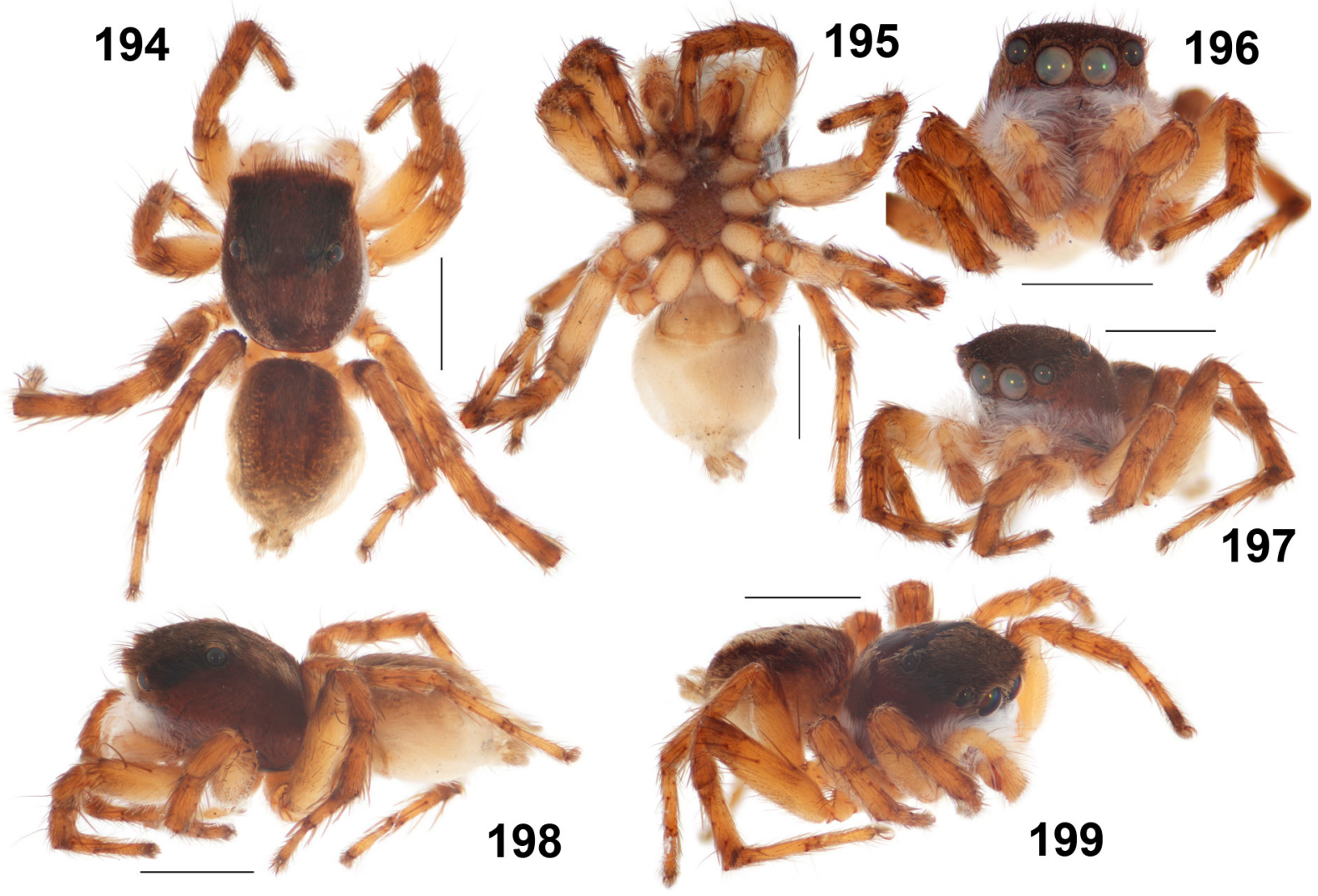

Figs 194-199. Manzuma tanzanica gen. et sp. nov., holotype, đ̊ , general appearance. Scale bars: $1 \mathrm{~mm}$. 
+ 0.60 (4.40). Leg spination: I: Fm d 0-1-1-5; Pt pr and rt 1; Tb d 1-0-0, pr 1-1-1, rt 0-1-0, v 2-2-2 ap; Mt pr and rt 1-1 ap, v 2-2 ap. II: Fm d 0-1-2-5; Pt pr and rt 1; Tb d 1-0-0; pr 1-1-1, rt 0-1-0; v 1-1-2 ap; Mt pr and rt 1-1ap, v 2-2 ap. III: Fm d 0-1-3-5; Pt pr and rt 1; Tb d 1-0-0, pr and rt 1-1-1-1, v 1-0-2 ap; Mt d 1-1-0, pr and rt 1-0-2 ap, v 1-1-2 ap. IV: Fm d 0-1-1-5; Pt pr and rt 1; Tb d 1-0-0, pr and rt 1-1-11, v 1-0-2 ap; Mt d 1-1-0, pr 1-1-2 ap, rt 1-0-2 ap, v 1-1-2 ap. Coloration (in alcohol; Figs 194-199). Carapace brown, eye field dark brown, covered with brown scales, with two longitudinal stripes of white scales, sides covered with white stripes of scales. Sternum yellow-brown. Endites, labium and chelicerae brown-yellow. Clypeus and cheeks brown, densely covered with long white hairs; apical half of cheeks under ALEs covered with short brown scales. Abdomen: dorsum brown, medially with longitudinal white stripe; ventral grey-yellow. Book-lung covers brownish yellow. Spinnerets: anterior yellow, posterior brownish. All legs brownish yellow. Femora of all legs apically brown. Patellae, tibiae, metatarsi and tarsi of all legs yellow to brownish. Palps yellow, covered with long white hairs; cymbium yellow. Palpal structure as in Figs 188-193: tegulum with clearly visible proximal projection; apical projection small; TA paddle-shaped.

\section{Distribution}

Tanzania (Fig. 200).

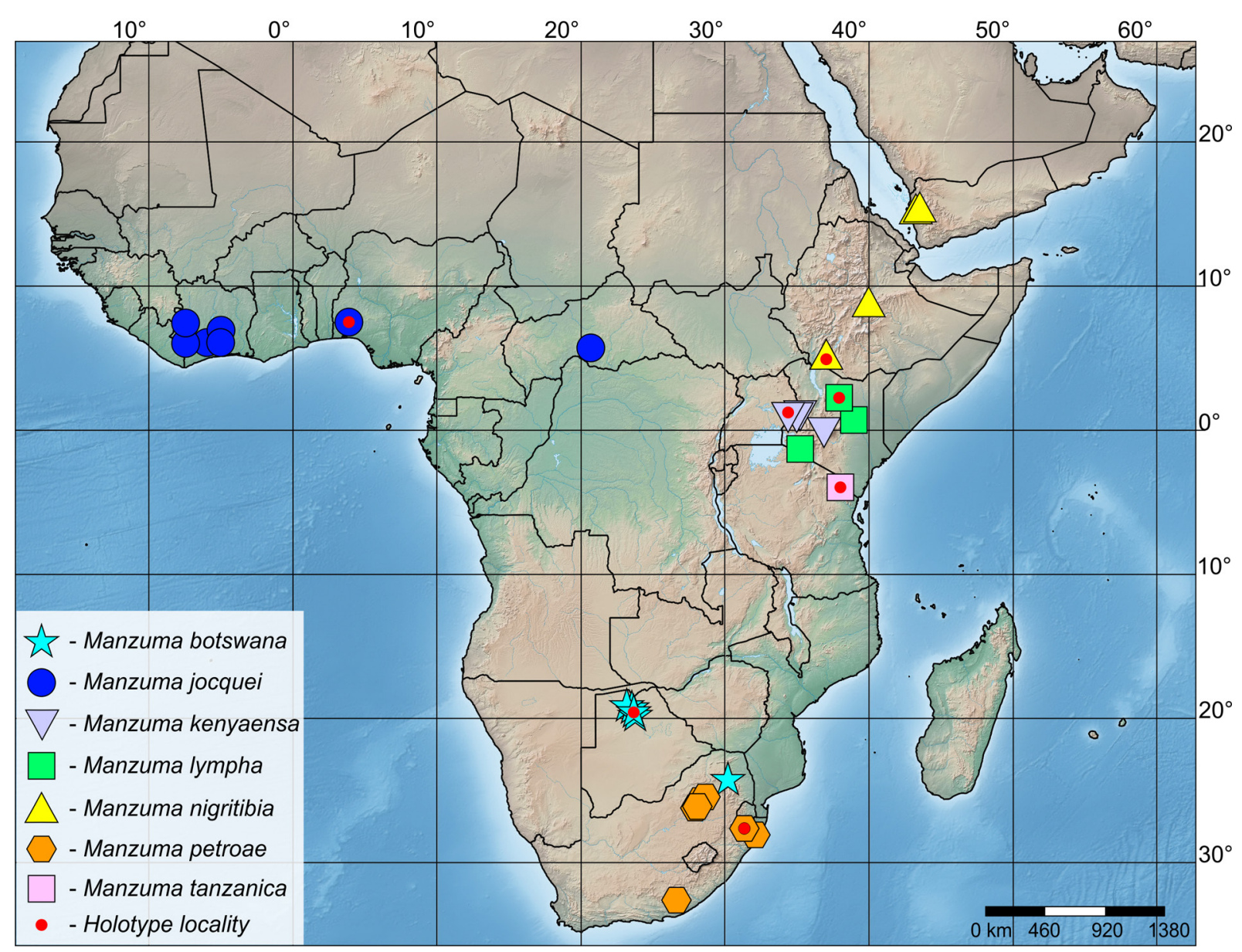

Fig. 200. Collecting localities of seven species of Manzuma gen. nov. 


\section{Discussion}

To date, the genus Manzuma gen. nov. is the first and the only endemic genus of aelurillines described from the Afrotropical Region. Although only seven species are known, the genus is likely to contain more undescribed species from different African regions, and its current species richness is underestimated. Underestimation of aelurilline diversity is not isolated to Manzuma gen. nov., but rather throughout aelurillines. There are undescribed endemic aelurilline genera from Africa awaiting description, with some of their species being mistakenly assigned to such genera as Aelurillus, Langona, Langelurillus and Phlegra (unpubl. data).

The currently-known world Aelurillina fauna contains 291 species in ten genera, including the Manzuma gen. nov. The Afrotropical Region (sensu Dippenaar-Schoeman \& Jocqué 1997) includes 125 Aelurillina species in seven genera, which is almost $43 \%$ of the world diversity of Aelurillina (Table 1). It is

\section{West \& Central Africa}

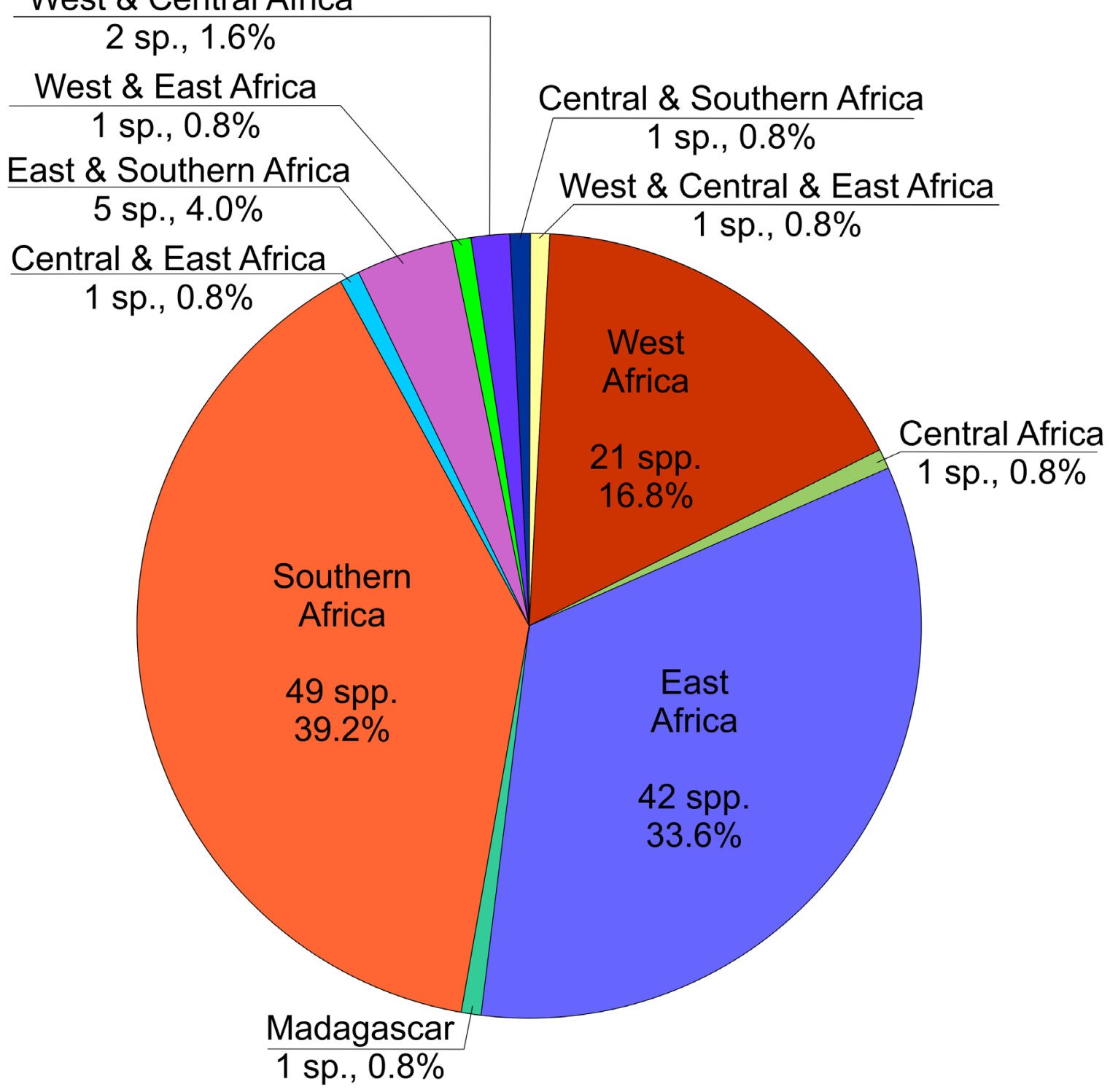

Fig. 201. Proportions of aelurilline species in different subregions of Afrotropics. 
Table 1 (continued in next pages). Species composition and distribution of Aelurillina Simon, 1901 in Afrotropical Region.

\begin{tabular}{|c|c|c|}
\hline Genera and species & Distribution & Subregion \\
\hline \multicolumn{3}{|c|}{ Aelurillus Simon, 1884} \\
\hline A. catus Simon, 1886 & Senegal & West Africa \\
\hline A. cristatopalpus Simon, 1902 & South Africa & Southern Africa \\
\hline A. madagascariensis Azarkina, 2009 & Madagascar & Madagascar \\
\hline A. minutus Azarkina, 2002 & Eritrea & East Africa \\
\hline A. mirabilis Wesołowska, 2006 & Namibia & Southern Africa \\
\hline A. rugatus (Bösenberg \& Lenz, 1895) & Tanzania & East Africa \\
\hline A. russellsmithi Azarkina, 2009 & Côte d'Ivoire & West Africa \\
\hline A. subaffinis Caporiacco, 1947 & Ethiopia & East Africa \\
\hline A. tumidulus Wesołowska \& Tomasiewicz, 2009 & Ethiopia & East Africa \\
\hline \multicolumn{3}{|c|}{ Langelurillus Próchniewicz, 1994} \\
\hline L. alboguttatus Wesołowska \& Russell-Smith, 2000 & Tanzania & East Africa \\
\hline L. cedarbergensis Haddad \& Wesołowska, 2013 & South Africa & Southern Africa \\
\hline L. furcatus Wesołowska \& Russell-Smith, 2000 & Kenya, Tanzania & East Africa \\
\hline L. holmi Próchniewicz, 1994 & Kenya & East Africa \\
\hline L. horrifer Rollard \& Wesołowska, 2002 & Guinea & East Africa \\
\hline L. ignorabilis Wesołowska \& Cumming, 2008 & Zimbabwe & Southern Africa \\
\hline L. krugeri Wesołowska \& Haddad, 2013 & South Africa & Southern Africa \\
\hline L. manifestus Wesołowska \& Russell-Smith, 2000 & Tanzania & East Africa \\
\hline L. minutus Wesołowska \& Cumming, 2008 & Namibia, Zimbabwe & Southern Africa \\
\hline L. namibicus Wesołowska, 2011 & Namibia, South Africa & Southern Africa \\
\hline L. nigritus (Berland \& Millot, 1941) & $\begin{array}{l}\text { Côte d'Ivoire, Guinea, } \\
\text { Nigeria }\end{array}$ & West Africa \\
\hline L. orbicularis Wesołowska \& Cumming, 2008 & Zimbabwe & Southern Africa \\
\hline L. primus Próchniewicz, 1994 & Kenya & East Africa \\
\hline L. quadrimaculatus Wesołowska \& Russell-Smith, 2011 & Nigeria & West Africa \\
\hline L. rufus (Lessert, 1925) & Ethiopia, Tanzania & East Africa \\
\hline L. sibandai Wesołowska, 2011 & Zimbabwe & Southern Africa \\
\hline L. spinosus Próchniewicz, 1994 & Kenya & East Africa \\
\hline L. squamiger Wesołowska \& Haddadm 2018 & South Africa & Southern Africa \\
\hline
\end{tabular}


Table 1 (continued).

\begin{tabular}{|c|c|c|}
\hline Genera and species & Distribution & Subregion \\
\hline \multicolumn{3}{|c|}{ Langona Simon, 1901} \\
\hline L. alfensis Hęciak \& Prószyński, 1983 & Sudan, Ethiopia & East Africa \\
\hline L. avara Peckham \& Peckham, 1903 & Southern Africa & Southern Africa \\
\hline L. bethae Wesołowska \& Cumming, 2011 & Botswana, Zimbabwe & Southern Africa \\
\hline L. bisecta Lawrence, 1927 & Namibia & Southern Africa \\
\hline L. bitumorata Próchniewicz \& Hęciak, 1994 & Tanzania & East Africa \\
\hline L. bristowei Berland \& Millot, 1941 & West, Central Africa & West Africa \\
\hline L. fusca Wesołowska, 2011 & Zimbabwe & Southern Africa \\
\hline L. hirsuta Haddad \& Wesołowska, 2011 & South Africa & Southern Africa \\
\hline L. improcera Wesołowska \& Russell-Smith, 2000 & Tanzania & East Africa \\
\hline L. lotzi Haddad \& Wesołowska, 2011 & Lesotho, South Africa & Southern Africa \\
\hline L. magna Caporiacco, 1947 & East Africa & East Africa \\
\hline L. maindroni (Simon, 1886) & Senegal & West Africa \\
\hline L. manicata Simon, 1901 & South Africa & Southern Africa \\
\hline L. mediocris Wesołowska, 2000 & Zimbabwe & Southern Africa \\
\hline L. minima Caporiacco, 1949 & Kenya & Eastern Africa \\
\hline L. pecten Próchniewicz \& Hęciak, 1994 & $\begin{array}{l}\text { Kenya, Tanzania, } \\
\text { Zimbabwe }\end{array}$ & $\begin{array}{l}\text { East \& Southern } \\
\text { Africa }\end{array}$ \\
\hline L. pilosa Wesołowska, 2006 & Namibia & Southern Africa \\
\hline L. redii (Audouin, 1826) & Yemen & East Africa \\
\hline L. sabulosa Wesołowska, 2011 & Namibia & East Africa \\
\hline L. senegalensis Berland \& Millot, 1941 & Senegal & Southern Africa \\
\hline L. tartarica (Charitonov, 1946) & Yemen & East Africa \\
\hline L. tortuosa Wesołowska. 2011 & $\begin{array}{l}\text { Namibia, South Africa, } \\
\text { Zimbabwe }\end{array}$ & Southern Africa \\
\hline L. trifoveolata (Lessert, 1927) & Congo & Central Africa \\
\hline L. ukualuthensis Lawrence, 1927 & Namibia & Southern Africa \\
\hline L. vitiosa Wesołowska. 2006 & Namibia & Southern Africa \\
\hline L. warchalowskii Wesołowska, 2007 & South Africa & Southern Africa \\
\hline L. zimbabwensis Wesołowska \& Cumming, 2011 & Zimbabwe & Southern Africa \\
\hline
\end{tabular}


Table 1 (continued).

\begin{tabular}{|c|c|c|}
\hline Genera and species & Distribution & Subregion \\
\hline \multicolumn{3}{|c|}{ Manzuma gen. nov. } \\
\hline M. botswana gen. et sp. nov. & Botswana, South Africa & Southern Africa \\
\hline $\begin{array}{l}\text { M. jocquei (Azarkina, Wesołowska \& Russell-Smith, } \\
\text { 2011) gen. et comb. nov. }\end{array}$ & $\begin{array}{l}\text { Central African Republic, } \\
\text { Côte d'Ivoire, Nigeria }\end{array}$ & $\begin{array}{l}\text { West \& Central } \\
\text { Africa }\end{array}$ \\
\hline $\begin{array}{l}\text { M. kenyaensis Dawidowicz \& Wesołowska, } 2016 \\
\text { gen. et comb. nov. }\end{array}$ & Kenya & East Africa \\
\hline $\begin{array}{l}\text { M. lympha (Próchniewicz \& Hęciak, 1994) } \\
\text { gen. et comb. nov. }\end{array}$ & Kenya & East Africa \\
\hline M. nigritibia (Caporiacco, 1941) gen. et comb. nov. & Ethiopia, Yemen & East Africa \\
\hline M. petroae gen. et sp. nov. & South Africa & Southern Africa \\
\hline M. tanzanica gen. et sp. nov. & Tanzania & East Africa \\
\hline
\end{tabular}

Phlegra Simon, 1876

P. abessinica Strand, 1906

P. albostriata Simon, 1901

P. arborea Wesołowska \& Haddad, 2009

P. atra Wesołowska \& Tomasiewicz, 2008

P. bairstowi Simon, 1886

P. bifurcata Schmidt \& Piepho, 1994

P. certa Wesołowska \& Haddad, 2009

P. chrysops Simon, 1890

P. crumena Próchniewicz \& Hęciak, 1994

P. desquamata Strand, 1906

P. etosha Logunov \& Azarkina, 2006

P. gagnoa Logunov \& Azarkina, 2006

P. imperiosa Peckham \& Peckham, 1903

P. insulana Schmidt \& Krause, 1998

P. karoo Wesołowska, 2006

P. langanoensis Wesołowska \& Tomasiewicz, 2008

P. levis Próchniewicz \& Hęciak, 1994

P. lugubris Berland \& Millot, 1941
Ethiopia

Lesotho, Mozambique, South Africa

South Africa

Ethiopia

South Africa

Cabo Verde

South Africa

Yemen

Kenya

Ethiopia

Namibia, South Africa

Côte d'Ivoire

South Africa

Cabo Verde

Namibia, South Africa,

Zimbabwe

Ethiopia, Zimbabwe

Kenya

West Africa

\section{East Africa}

Southern Africa

Southern Africa

East Africa

Southern Africa

West Africa

Southern Africa

East Africa

East Africa

East Africa

Southern Africa

West Africa

Southern Africa

West Africa

Southern Africa

East \& Southern

Africa

East Africa

West Africa 
Table 1 (continued).

Genera and species

P. nuda Próchniewicz \& Hęciak, 1994

P. parvula Wesołowska \& Russell-Smith, 2000

P. procera Wesołowska \& Cumming, 2008

P. pusilla Wesołowska \& van Harten, 1994

P. simplex Wesołowska \& Russell-Smith, 2000

P. solitaria Wesołowska \& Tomasiewicz, 2008

P. soudanica Berland \& Millot, 1941

P. suaverubens Simon, 1886

P. tenella Wesołowska, 2006

P. tetralineata (Caporiacco, 1939)

P. touba Logunov \& Azarkina, 2006

P. tristis Lessert, 1927

P. varia Wesołowska \& Russell-Smith, 2000
Distribution

Ethiopia, Kenya, Tanzania, East \& Southern

Uganda, Zimbabwe

Tanzania

Zimbabwe

Yemen, Senegal to

Zimbabwe

Tanzania, Zimbabwe

Ethiopia

Mali

Senegal

Namibia

Ethiopia

Côte d'Ivoire, Nigeria

Congo, Kenya

Tanzania
Subregion

Africa

East Africa

Southern Africa

East \& Southern

Africa

East \& Southern

Africa

East Africa

West Africa

West Africa

Southern Africa

East Africa

West Africa

Central \& East Africa

East Africa

Rafalus Prószyński, 1999

R. insignipalpis (Simon, 1882)

Yemen

East Africa

Stenaelurillus Simon, 1886

S. albopunctatus Caporiacco, 1949

S. bandama Logunov \& Azarkina, 2018

S. brandbergensis (Wesołowska, 2006)

S. darwini Wesołowska \& Russell-Smith, 2000

S. furcatus Wesołowska, 2014

S. fuscatus Wesołowska \& Russell-Smith, 2000

S. glaber Wesołowska \& Russell-Smith, 2011

S. guttatus (Wesołowska \& Cumming, 2002)

S. guttiger (Simon, 1901)

S. hirsutus Lessert, 1927

S. ignobilis Wesołowska \& Cumming, 2011
Kenya

Côte d'Ivoire

Namibia

Kenya, Tanzania

Namibia

Kenya, Tanzania

Ghana, Nigeria, Uganda

Botswana, Namibia,

Zambia, Zimbabwe

Botswana, Mozambique,

South Africa, Zimbabwe

Congo, Central Africa, Ghana, Kenya, Senegal, Tanzania, Uganda

Zimbabwe
East Africa

West Africa

Southern Africa

East Africa

Southern Africa

East Africa

West \& East Africa

Southern Africa

Southern Africa

West \& Central \&

East Africa

Southern Africa 
Table 1 (continued).

\begin{tabular}{|c|c|c|}
\hline Genera and species & Distribution & Subregion \\
\hline S. iubatus Wesołowska \& Russell-Smith, 2011 & Nigeria & West Africa \\
\hline S. jocquei Logunov \& Azarkina, 2018 & Cameroon & West Africa \\
\hline S. kavango Wesołowska, 2014 & Namibia & Southern Africa \\
\hline S. kronestedti Próchniewicz \& Hęciak, 1994 & Tanzania & East Africa \\
\hline S. latibulbis Wesołowska, 2014 & Congo, Zambia & $\begin{array}{l}\text { Central \& Southern } \\
\text { Africa }\end{array}$ \\
\hline S. leucogrammus Simon, 1902 & Mozambique, Zimbabwe & Southern Africa \\
\hline S. mirabilis Wesołowska \& Russell-Smith, 2000 & Kenya, Tanzania & East Africa \\
\hline S. modestus Wesołowska, 2014 & South Africa & Southern Africa \\
\hline S. nigricaudus Simon, 1886 & $\begin{array}{l}\text { Burkina Faso, Gambia, } \\
\text { Mali, Niger, Senegal }\end{array}$ & West Africa \\
\hline S. pecten Wesołowska, 2014 & Botswana, Zambia & Southern Africa \\
\hline S. pilosus Wesołowska \& Russell-Smith, 2011 & Nigeria & West Africa \\
\hline S. pseudoguttatus Logunov \& Azarkina, 2018 & Namibia & Southern Africa \\
\hline S. senegalensis Logunov \& Azarkina, 2018 & Senegal & West Africa \\
\hline S. siyamae Logunov \& Azarkina, 2018 & Sudan & East Africa \\
\hline S. specularis Wesołowska, 2014 & Malawi & Southern Africa \\
\hline S. strandi Caporiacco, 1939 & Ethiopia & East Africa \\
\hline S. striolatus Wesołowska \& Russell-Smith, 2011 & Nigeria & West Africa \\
\hline S. sudanicus Wesołowska, 2014 & Sudan & East Africa \\
\hline S. termitophagus (Wesołowska \& Cumming, 1999) & $\begin{array}{l}\text { Botswana, Namibia, South } \\
\text { Africa }\end{array}$ & Southern Africa \\
\hline S. uniguttatus Lessert, 1925 & Ethiopia, East Africa & East Africa \\
\hline S. zambiensis Wesołowska, 2014 & $\begin{array}{l}\text { Malawi, Zambia, } \\
\text { Zimbabwe }\end{array}$ & Southern Africa \\
\hline
\end{tabular}

worth mentioning that the modern chorological centers of the subtribe Aelurillina lie in the Afrotropical Region and the south part of the Palaearctics (see also Logunov \& Azarkina 2018 for a detailed review of subtribe Aelurillina).

To date, only one aelurilline species - Aelurillus madagascariensis Azarkina, 2009 - is known from the Madagascar zoogeographical Region (sensu Kryzhanovski 2002) (Table 1). The spider fauna of Madagascar Region remains poorly known, with only 105 species in 33 genera being recorded from there since the first publication (Vinson 1863; WSC 2019). At least one more Aelurillina genus, in addition to Aelurillus, was recently found in Madagascar (W. Maddison, pers. com.). 
The most abundant subregions of Afrotropics are South Africa, with 49 species (39.2 \% of all Afrotropical aelurillines), and East Africa, with 42 species (33.6\%). Surprisingly, the most insect-rich subregion of Afrotropical Region, West Africa, contains only 21 aelurilline species (16.8\%). This could be explained by two reasons. First, the aelurillines are ground-dwellers that seem to prefer dry open biotopes with high insolation, whereas in West Africa the most common biotopes are humid tropical forest. The second and more probable reason could be insufficient knowledge of spider fauna of that subregion. The same holds true for Central Africa, with only one aelurilline species $(0.8 \%)$ being described from this region to date. Ten species are known from two or three subregions (Fig. 193). East and South Africa share five species (4.0\%), West and Central - two species (1.6\%). Central and East and Central and South Africa share one species each (0.8\%) (Fig. 201). One species (0.8\%) - Stenaelurilus hirsutus - is found in West, Central and East Africa. The most unusual distribution is known for Stenaelurillus glaber, which is found in West and East Africa (Table 1).

Five Aelurillina genera - Aelurillus, Asianellus, Manzuma gen. nov., Proszynskiana and Stenaelurillus - have recently been revised or described. The genera Langelurillus, Langona, Phlegra and Rafalus are in need of a taxonomic revision. The taxonomic problem of the genus Phanuelus and Asian members of Langleurillus is in need of special attention in the future (see also discussion in Logunov \& Azarkina 2018).

\section{Acknowledgements}

I wish to express my warmest thanks to all curators listed above under 'Material and methods' for allowing me to study the material from their museums, to Anthony Russell-Smith (Sittingbourne, UK) for allowing me to study material from his personal collection and providing me with data on J.-C. Ledoux's collection. I also want to cordially thank Stefan Foord (Louis Trichard, RSA), Charles Haddad (Bloemfontein, RSA), Ansie Dippenaar-Schoeman, Petro Marais, Robyn Lyle and Vida van der Walt (Pretoria/Tshwane, RSA), as well as Astri and John Leroy (Roodepoort, Johannesburg, RSA) and Norman and Dawn Larsen (Cape Town, RSA) for their kind help during my stay in South Africa. I am grateful to Vida van der Walt for allowing me to use her photos of living specimens in this publication. Peter Jäger and Julia Altmann (Frankfurt am Main, Germany) are cordially thanked for giving me an opportunity to work with the Senckenberg collection. I am much obliged to Dmitri Logunov (Manchester, UK), Anthony Russell-Smith and Wanda Wesołowska (Wrocław, Poland) for their support and inspiration, their long-term discussions about Aelurillines, and various and important inputs during the preparation of this paper. Special thanks go to Anthony Russell-Smith and Dmitri Logunov for editing the English of the final draft. Finally, I wish to thank Wayne Paul Maddison (Vancouver, Canada) and an anonymous referee for their critical comments that helped to improve it. This work was partly supported by the Federal Fundamental Scientific Research Programme for 20132020 (No. AAAA-A16-116121410121-7, NRF grant (CPRR) for 2015 (\#95569) and Taxonomy Grant from Senckenberg Fellowship.

\section{References}

Azarkina G.N. 2002. New and poorly known species of the genus Aelurillus Simon, 1884 from central Asia, Asia Minor and the eastern Mediterranean (Araneae: Salticidae). Bulletin of the British Arachnological Society 12 (6): 249-263.

Azarkina G.N. 2003. Aelurillus ater (Kroneberg, 1875) and related species of jumping spiders in the fauna of middle Asia and the Caucasus (Aranei: Salticidae). Arthropoda Selecta 11 (1): 89-107.

Azarkina G.N. 2006. Revision of the genus Aelurillus Simon, 1884 (Salticidae) of the world. Synopsis of $P h D$ thesis. Novosibirsk, ISEA SB RAS.

Azarkina G.N. 2009. Two new species of the genus Aelurillus Simon, 1885 (Araneae, Salticidae) from Africa. Journal of Afrotropical Zoology 5: 171-177. 
Azarkina G.N. \& Zamani A. 2019. The Aelurillina Simon, 1901 (Aranei: Salticidae) of Iran: a check-list and three new species of Aelurillus Simon, 1884 and Proszynskiana Logunov, 1996. Arthropoda Selecta 28 (1): 83-97. https://doi.org/10.15298/arthsel.28.1.07

Azarkina G.N., Zoumides C. \& Hadjiconstantis M. 2018. First description of the female of Aelurillus cypriotus Azarkina, 2006 (Araneae: Salticidae). Acta Arachnologica 67 (1): 49-54.

https://doi.org/10.2476/asjaa.67.49

Caporiacco L. di 1941. Arachnida (esc. Acarina). Araneae. Missione Biologica Sagan-Omo, Reale Accademia d'Italia, Roma 12 (Zoologia 6): 46-175.

Dawidowicz A. \& Wesołowska W. 2016. Jumping spiders (Araneae: Salticidae) of Kenya collected by Åke Holm. Annales Zoologici 66 (3): 437-466.

https://doi.org/10.3161/00034541ANZ2016.66.3.010

Dippenaar-Schoeman A.S. \& Jocqué R. 1997. African Spiders: An Identification Manual. Plant Protection Research Institute Handbook, 9.

Kryzhanovsky O.L. 2002. Composition and Distribution of Entomofaunas of the Globe. KMK Scientific Press Ltd, Moscow.

Logunov D.V. 1996a. Salticidae of Middle Asia. 3. A new genus, Proszynskiana gen. nov., in the subfamily Aelurillinae (Araneae, Salticidae). Bulletin of the British Arachnological Society 10 (5): 171177.

Logunov D.V. 1996b. A review of the genus Phlegra Simon, 1876 in the fauna of Russia and adjacent countries (Araneae: Salticidae: Aelurillinae). Genus 7: 533-567.

Logunov D.V. \& Azarkina G.N. 2018. Redefinition and partial revision of the genus Stenaelurillus Simon, 1886 (Arachnida, Araneae, Salticidae). European Journal of Taxonomy 430: 1-126. https://doi.org/10.5852/ejt.2018.430

Logunov D.V. \& Hęciak S. 1996. Asianellus, a new genus of the subfamily Aelurillinae (Araneae: Salticidae). Entomologica Scandinavica 26 (1): 103-117. https://doi.org/10.1163/187631296X00223

Maddison W.P. 1996. Pelegrina Franganillo and other jumping spiders formerly placed in the genus Metaphidippus (Araneae: Salticidae). Bulletin of the Museum of Comparative Zoology 154 (4): 215-368.

Maddison W.P. 2015. A phylogenetic classification of jumping spiders (Araneae: Salticidae). Journal of Arachnology 43 (3): 231-292. https://doi.org/10.1636/arac-43-03-231-292

Ono H. 1988. A Revisional Study of the Spider Family Thomisidae (Arachnida, Araneae) of Japan. National Science Museum, Tokyo.

Próchniewicz M. 1994. The jumping spiders of the Ethiopian Region. Part I. New genus Langelurillus gen. nov. (Araneae, Salticidae) from Kenya. Annales Zoologici 45: 27-31.

Próchniewicz M. \& Hęciak S. 1994. The jumping spiders of the Ethiopian Region. Part II. New species of Aelurillus, Langona, Phlegra, Stenaelurillus (Araneae, Salticidae) from Kenya and Tanzania. Annales Zoologici 45: 33-41.

Prószyński J. 1987. Atlas rysinków diagnistychnych mniej znanych Salticidae 2. Zeszyty Naukowe Wyższej Szkoly Polniczo-Pedagogicznej Siedlcach.

Prószyński J. 1999. Description of Rafalus gen. nov. (Aranei: Salticidae), with special reference to the Near East fauna. Arthropoda Selecta 8 (2): 89-101.

Prószyński J. 2003. Salticidae (Aeaneae) of the Levant. Annales Zoologici 53 (1): 1-180. 
Prószyński J. 2017. Pragmatic classification of the world's Salticidae (Araneae). Ecologica Montenegrina 12: $1-133$.

Shorthouse D.P. 2010. SimpleMappr, an online tool to produce publication-quality point maps. Available from http://www.simplemappr.net [accessed 23 Sep. 2019].

Vinson A. 1863. Aranéides des Îles de la Réunion, Maurice et Madagascar. Roret, Paris.

Wesołowska W. 2014a. A review of the Asian species of the spider genus Stenaelurillus (Araneae: Salticidae). Oriental Insects 47 (4): 246-254. https://doi.org/10.1080/00305316.2013.871823

Wesolowska W. 2014b. Further notes on the genus Stenaelurillus Simon, 1885 (Araneae, Salticidae) in Africa with descriptions of eight new species. Zoosystema 36 (3): 595-622.

https://doi.org/10.5252/z2014n3a3

Wesołowska W. \& Russell-Smith A. 2000. Jumping spiders from Mkomazi Game Reserve in Tanzania (Araneae Salticidae). Tropical Zoology 13: 11-127. https://doi.org/10.1080/03946975.2000.10531126

Wesołowska W. \& Russell-Smith A. 2011. Jumping spiders (Araneae: Salticidae) from southern Nigeria. Annales Zoologici 61 (3): 553-619.

Wesołowska W. \& van Harten A. 1994. Additions to the knowledge of jumping spiders (Araneae: Salticidae) of Yemen. Fauna of Arabia 23: 189-269.

Wesołowska W. \& van Harten A. 2010. Order Araneae, Family Salticidae. In: van Harten A. (ed.) Arthropod Fauna of the UAE. vol. 33: 27-69. Dar Al Ummah, Abu Dhabi.

Wesołowska W. \& Tomasiewicz B. 2008. New species and records of Ethiopian jumping spiders (Araneae, Salticidae). Journal of Afrotropical Zoology 4: 3-59.

WSC 2019. World Spider Catalog, version 20.5. Natural History Museum, Bern.

Available from http://wsc.nmbe.ch [accessed 23 Sep. 2019] https://doi.org/10.24436/2

Manuscript received: 1 October 2019

Manuscript accepted: 26 November 2019

Published on: 5 March 2020

Topic editor: Rudy Jocqué

Desk editor: Pepe Fernández

Printed versions of all papers are also deposited in the libraries of the institutes that are members of the EJT consortium: Muséum national d'histoire naturelle, Paris, France; Meise Botanic Garden, Belgium; Royal Museum for Central Africa, Tervuren, Belgium; Royal Belgian Institute of Natural Sciences, Brussels, Belgium; Natural History Museum of Denmark, Copenhagen, Denmark; Naturalis Biodiversity Center, Leiden, the Netherlands; Museo Nacional de Ciencias Naturales-CSIC, Madrid, Spain; Real Jardín Botánico de Madrid CSIC, Spain; Zoological Research Museum Alexander Koenig, Bonn, Germany; National Museum, Prague, Czech Republic. 